\title{
Isotopic composition of water in the tropical tropopause layer in cloud-resolving simulations of an idealized tropical circulation
}

\section{Citation}

Blossey, Peter N., Zhiming Kuang, and David M. Romps. 2010. “Isotopic Composition of Water in the Tropical Tropopause Layer in Cloud-Resolving Simulations of an Idealized Tropical Circulation: WATER ISOTOPOLOGUES IN THE TTL." Journal of Geophysical Research: Atmospheres115 (D24). https://doi.org/10.1029/2010JD014554.

\section{Permanent link}

http://nrs.harvard.edu/urn-3:HUL.InstRepos:41534411

\section{Terms of Use}

This article was downloaded from Harvard University's DASH repository, and is made available under the terms and conditions applicable to Other Posted Material, as set forth at http:// nrs.harvard.edu/urn-3:HUL.InstRepos:dash.current.terms-of-use\#LAA

\section{Share Your Story}

The Harvard community has made this article openly available.

Please share how this access benefits you. Submit a story.

\section{Accessibility}




\title{
Isotopic composition of water in the tropical tropopause layer in cloud-resolving simulations of an idealized tropical circulation
}

\author{
Peter N. Blossey, ${ }^{1}$ Zhiming Kuang, ${ }^{2}$ and David M. Romps ${ }^{2}$ \\ Received 30 May 2010; revised 20 September 2010; accepted 30 September 2010; published 21 December 2010.
}

[1] The processes that fix the fractionation of the stable isotopologues of water in the tropical tropopause layer (TTL) are studied using cloud-resolving model simulations of an idealized equatorial Walker circulation with an imposed Brewer-Dobson circulation. This simulation framework allows the explicit representation of the convective and microphysical processes at work in the TTL. In this model, the microphysical transfer of the isotopologues (here, $\mathrm{HD}^{16} \mathrm{O}$ and $\mathrm{H}_{2}^{18} \mathrm{O}$ ) among water vapor and condensed phase hydrometeors is explicitly represented along with those of the standard isotopologue $\left(\mathrm{H}_{2}^{16} \mathrm{O}\right)$ during all microphysical interactions. The simulated isotopic ratios of $\mathrm{HD}^{16} \mathrm{O}$ in water vapor are consistent with observations in both magnitude and the vertical structure in the TTL. When a seasonal cycle is included in the Brewer-Dobson circulation, both the water vapor mixing ratio and the isotopic ratios of water vapor display a seasonal cycle as well. The amplitude and phase of the seasonal cycle in $\mathrm{HD}^{16} \mathrm{O}$ are comparable to those observed. The results suggest that both the sublimation of relatively enriched ice associated with deep convection and fractionation by cirrus cloud formation affect the isotopic composition of water vapor in the TTL and its seasonal cycle.

Citation: Blossey, P. N., Z. Kuang, and D. M. Romps (2010), Isotopic composition of water in the tropical tropopause layer in cloud-resolving simulations of an idealized tropical circulation, J. Geophys. Res., 115, D24309, doi:10.1029/2010JD014554.

\section{Introduction}

[2] Water vapor in the stratosphere plays an important role in the climate and chemistry of the stratosphere and also of the Earth as a whole [e.g., Forster and Shine, 1999; Kirk-Davidoff et al., 1999; Shindell, 2001]. The issue of what sets the stratospheric humidity has drawn much attention, especially in light of the apparent and controversial trend in stratospheric water over the past few decades [e.g., Rosenlof et al., 2001]. More recently, Solomon et al. [2010] suggested that apparent trends in stratospheric water vapor have likely modulated the effect of increasing greenhouse gas forcings, with decreases in stratospheric water vapor after 2000 offsetting in part the increased greenhouse gas forcing during the past decade.

[3] Air enters the stratosphere mainly through the tropical upper troposphere, where it is drawn upward by the ascending branch of the Brewer-Dobson circulation [Brewer, 1949]. The low water vapor levels in the stratosphere result from low-saturation vapor pressures associated with the cold temperatures in the vicinity of the tropical tropopause. In the tropics, there is not a sharp interface between the troposphere and stratosphere. Rather, a region of mixed stratospheric and

\footnotetext{
${ }^{1}$ Atmospheric Sciences, University of Washington, Seattle, Washington, USA.

${ }^{2}$ Department of Earth and Planetary Sciences, Harvard University, Cambridge, Massachusetts, USA.
}

Copyright 2010 by the American Geophysical Union. 0148-0227/10/2010JD014554 tropospheric properties, called the tropical tropopause layer (TTL), exists between about 14 and $18.5 \mathrm{~km}$ altitude. See the recent review by Fueglistaler et al. [2009] for a detailed description.

[4] There remains uncertainty about the mechanisms through which the water vapor content of air entering the stratosphere is fixed. Many mechanisms have been proposed including: gradual dehydration by cirrus formation as air is advected through relatively cold regions [e.g., Holton and Gettelman, 2001], dehydration by the injection of dry air by deep convective events [e.g., Sherwood and Dessler, 2001], hydration by overshooting deep convection through the injection and subsequent sublimation of ice [e.g., Corti et al., 2008], dehydration by thin cirrus formation above deep cold cloud tops [Hartmann et al., 2001] and others.

[5] As first proposed by Moyer et al. [1996], the stable isotopologues of water (here, $\mathrm{HD}^{16} \mathrm{O}$ and $\mathrm{H}_{2}^{18} \mathrm{O}$ ), whose concentrations relative to the standard isotopologue $\mathrm{H}_{2}^{16} \mathrm{O}$ contain information about the history of parcels entering the stratosphere, may shed some light on the relative contribution of the proposed mechanisms for fixing the water vapor content of the stratosphere. These heavy isotopologues of water condense more readily than the standard isotopologue $\mathrm{H}_{2}^{16} \mathrm{O}$, so a greater proportion of the heavy isotopologues of water vapor are removed as air ascends through the troposphere. The remaining vapor in the upper troposphere is said to be depleted, or light, when compared to the vapor in the lower troposphere because it has a smaller ratio of deuterium to hydrogen in vapor (similar for ${ }^{18} \mathrm{O}$ to ${ }^{16} \mathrm{O}$ ). These isotopic 
ratios are characterized by their relation to that in a standard (Vienna standard mean ocean water, SMOW):

$$
\delta D=\frac{([D] /[H])_{\text {sample }}}{([D] /[H])_{\text {SMOW }}}-1
$$

using deuterium as an example. Note that $\delta D$ is often expressed as "per mil", and a sample with no deuterium has $\delta D=-1000 \%$ o (per mil). A sample whose deuterium to hydrogen ratio matches the standard has $\delta D=0 \%$. Vapor of condensate that has a relatively higher ratio of deuterium to hydrogen than another sample is said to be enriched, or heavy, in comparison to the other. An additional quantity, the deuterium excess $d=\delta D-8 \delta^{18} O$, is often used as an indicator of nonequilibrium (or kinetic) effects, such as evaporation, on the isotopic ratios [see, e.g., Dansgaard, 1964].

\subsection{Observational Studies}

[6] Using observation from the Atmospheric Trace Molecular Spectroscopy (ATMOS) instrument, Moyer et al. [1996] found that $\delta D$ of water vapor entering the stratosphere was much higher than that suggested by Rayleigh models that assume the immediate removal of condensate. They suggested that the sublimation of relatively enriched ice lofted by convection could be responsible for the discrepancy. Further work extending the ATMOS observations down into the TTL by Kuang et al. [2003] showed that $\delta D$ in water vapor was relatively uniform in the vertical with values around $-650 \%$, despite an approximately fivefold decrease in water vapor through these altitudes. The in situ observations of Webster and Heymsfield [2003] found a wide range of fractionations of $\delta D$ within the upper troposphere in and near deep convection and suggested that both gradual and convective mechanisms may be important in fixing the humidity of stratospheric air. Both Kuang et al. [2003] and Dessler and Sherwood [2003] suggested that mixing of parcels with differing $\delta D$ and water vapor amounts could contribute to the relatively uniform profile of $\delta D$ in the TTL, because the $\delta D$ of the mixture is largely determined by the parcel with the larger amount of water vapor. More recent in situ observations of $\delta D$ in water vapor by St Clair et al. [2008] and Sayres et al. [2010] have illuminated the variability in isotopic ratios in the TTL and found different vertical structures of $\delta D$ in data from two field experiments. In wintertime data from CR-AVE (Costa Rica Aura Validation Experiment), a minimum in $\delta D$ is apparent near the base of the TTL, while a more vertically uniform profile of $\delta D$ in the TTL was seen during the summertime TC4 (Tropical Composition, Cloud and Climate Coupling) campaign. A nice depiction of both in situ and satellite-based observations of $\delta D$ in the TTL can be found in Figure 10 of Fueglistaler et al. [2009].

[7] Observations by Nassar et al. [2007], Payne et al. [2007], Notholt et al. [2010] and Steinwagner et al. [2010] have explored the seasonal cycle in $\delta D$ of water vapor entering the stratosphere. Nassar et al. [2007] used ACE-FTS (Atmospheric Chemistry Experiment-Fourier Transform Spectrometer) measurements of temperature, water vapor and $\mathrm{HD}^{16} \mathrm{O}$ from 2004 and 2005 to infer that convective ice lofting and gradual dehydration both play roles in fixing the water vapor content entering the tropical stratosphere. A seasonal cycle in $\delta D$ was detected by Nassar et al. [2007] with minimum values in February and maxima in August, but the observed amplitude differed substantially between the northern and southern hemisphere tropics. Payne et al. [2007] also found a seasonal cycle in $\mathrm{HD}^{16} \mathrm{O}$ using MIPAS (Michelson Interferometer for Passive Atmospheric Sounding) with hints of a tape recorder structure in the vertical similar to that seen in water vapor [Mote et al., 1995]. The studies of Notholt et al. [2010] and Steinwagner et al. [2010], using a balloon-borne spectrometer (the JPL MkIV balloon-borne solar occultation Fourier transform infrared spectrometer) and new retrievals from MIPAS, respectively, found that the seasonal variations in $\delta D$ are largely determined by the seasonal variation in temperature of the tropopause and the cirrus clouds that fix the final $\delta D$ of air entering the stratosphere. In addition, seasonal variations in the lofting of ice by deep convection may play a smaller role in the observed seasonal variations in $\delta D$. Further, Steinwagner et al. [2010] find a tape recorder structure in time-height plots of observed $\delta D$ in the lower stratosphere that is analogous to that found for water vapor itself [Mote et al., 1995].

\subsection{Modeling Studies}

[8] The transport and fractionation of the stable isotopologues of water have been studied in models with widely ranging complexity. The most prominent analytical approach is Rayleigh fractionation [Dansgaard, 1964]. When attention is focused on the tropical tropopause layer, the more analytical approaches to the isotopic fractionation and transport there include calculations along trajectories [e.g., Gettelman and Webster, 2005] and conceptual models [e.g., Dessler and Sherwood, 2003; Read et al., 2008].

[9] As more processes and/or larger domains are considered, different models devote effort to the representation of different physical processes. Smith et al. [2006] have a detailed representation of convective and microphysical processes in their high-resolution, three-dimensional simulations of deep convection over sea surface temperatures characteristic of the tropical oceans. The high cost of the fine spatial resolution and bin microphysics lead to the use of repeated simulations of limited duration $(\sim 14 \mathrm{~h})$ in a small horizontal domain (24 km square). They find upper tropospheric water vapor to be relatively enriched in comparison to Rayleigh fractionation models and suggest that this enrichment is consistent with the sublimation of ice from lower in the troposphere. However, the statistics in the upper troposphere are not converged after their sequence of simulations, and the Brewer-Dobson circulation is neglected in their simulations due to its long time scale.

[10] Single-column models (SCMs) and isotope-enabled general circulation models (GCMs) employ a nonlocal, parameterized representation of convection. This complicates the treatment of isotopic exchanges in comparison to convection-resolving models-where isotopic exchanges are treated locally within microphysical parameterizationsbecause the microphysical exchanges in SCMs and GCMs can occur within multiple parameterizations, including both deep and shallow convection as well as stratiform microphysics. The assumptions within these parameterizations (e.g., the fraction of rain that falls within saturated air) could have an impact on the simulated isotopic ratios in 
precipitation and in the atmosphere. The more modest computational cost of a SCM allowed Bony et al. [2008] to perform a large ensemble of simulations that characterized the sensitivity of the isotopic content of precipitation, water vapor and condensate to varying sea surface temperature and large-scale vertical motion in simulations of radiative-convective equilibrium, as well as in simulations of TOGA-COARE using observationally derived forcings. While the focus of their study is the general characterization of their scheme and their simulations do not include a representation of the Brewer-Dobson circulation, they note that upper tropospheric water vapor is enriched relative to Rayleigh fractionation in radiative-convective equilibrium.

[11] Isotope GCMs eliminate many uncertainties with respect to forcings that are experienced in limited domain models, such as SCMs and CRMs, by coupling neighboring columns dynamically and through advection. Isotope GCMs generally reproduce the observed climatology of isotopes in precipitation and have been employed to explore isotopic effects in both current and past climates. Schmidt et al. [2005] evaluated the isotopic ratios of water vapor entering the lower stratosphere in an isotope-enabled version of the GISS GCM. While this model neglected the lofting of condensate by convective processes, the isotopic fractionation of water vapor entering the stratosphere was close to that observed, leading the authors to suggest that mixing likely plays a nonnegligible role in fixing the isotopic ratios of vapor in the TTL.

[12] Our goal in this study is to choose an approach of intermediate complexity and moderate computational cost that allows simulations of long duration (hundreds of days) that are cloud-resolving and include explicit representation of both large-scale circulations in the troposphere and the Brewer-Dobson circulation in the stratosphere. This inevitably involves tradeoffs. In our approach, this amounts to using a bulk microphysical parameterization (Smith et al. [2006] used a bin approach), a two-dimensional domain (3D from Smith et al. [2006]) and moderate horizontal resolution (2 km versus $375 \mathrm{~m}$ from Smith et al. [2006]). However, this enables the use of a relatively large twodimensional domain $(8096 \mathrm{~km})$ with fine vertical resolution through the TTL $(\leq 250 \mathrm{~m})$ over the hundreds of days required for the radiative, convective and transport processes to reach equilibrium in the TTL.

[13] This study asks: can we successfully simulate isotopic ratios in a large-scale radiative-convective equilibrium simulation? Are the isotopic ratios in the TTL consistent with those observed? Can we say something about the process or combination of processes that fix the isotopic ratios of water there (i.e., ice sublimation versus nonequilibrium processes versus mixing versus ...)? How sensitive is the distribution of isotopes to microphysics (cloud ice nucleation threshold, fallspeed of thin cirrus clouds), dynamical changes (seasonal modulation of $\mathrm{BD}$ circulation)?

\section{Model Description and Simulation Framework}

[14] The simulations described in this paper employ the System for Atmospheric Modeling (SAM), version 6.7 [Khairoutdinov and Randall, 2003], a cloud-resolving model that employs the anelastic approximation and can be used in conjunction with a variety of microphysical parameterizations. For the present study, the microphysical transformations of two stable, heavy isotopes of water $\left(\mathrm{HD}^{16} \mathrm{O}\right.$ and $\mathrm{H}_{2}^{18} \mathrm{O}$ ) have been added to the Lin microphysical scheme from the Weather and Research Forecasting model (WRF), version 3.1 [Skamarock and Klemp, 2008]. The WRF Lin scheme [Chen and Sun, 2002], which closely follows Lin et al. [1983], is a single-moment bulk scheme that performs a mixed-phase saturation adjustment (the saturation mixing ratio is a linear combination of that of liquid and ice in the range $-40 \leq T \leq 0^{\circ} \mathrm{C}$ ) and does not permit supersaturation with respect to ice at temperatures colder than $-40^{\circ} \mathrm{C}$. As observations suggest the widespread presence of supersaturation with respect to ice in the TTL [e.g., Spichtinger et al., 2003], the absence of supersaturation with respect to ice in the present microphysical scheme represent an unrealistic simplification in those regions. In future studies, more advanced microphysics schemes that represent supersaturation with respect to ice in a realistic way will be employed.

[15] The Lin scheme for the standard water isotope $\mathrm{H}_{2}^{16} \mathrm{O}$ has been extended in three main ways. First, errors in water conservation and spurious over production of graupel have been corrected. Second, the evaporation of rain is allowed for all relative humidities less than $100 \%$ (up from $90 \%$ before). (These bug fixes and extensions are present in the WRF 3.1.1 release.) Third, the treatment of the Bergeron process is modified to follow that of Krueger et al. [1995], which they found to lead to more abundant ice clouds that were in better agreement with observations in the tropics.

\subsection{Parameterization of Water Isotopes}

[16] In this microphysical scheme, all microphysical species and transformation processes of $\mathrm{H}_{2}^{16} \mathrm{O}$ have been duplicated for $\mathrm{HD}^{16} \mathrm{O}$ and $\mathrm{H}_{2}^{18} \mathrm{O}$. Here, the isotopic composition of a given microphysical species (e.g., rain) is assumed to be independent of the diameter of the particle. The mass exchange of the heavy isotopes in processes without fractionation (e.g., freezing) is in proportion to their relative concentration in the source species. For example, the freezing of $\mathrm{HD}^{16} \mathrm{O}$ in rain to form $\mathrm{HD}^{16} \mathrm{O}$ in graupel $\left(\mathrm{P}_{r f r z}^{\prime}\right)$ is assumed to depend on the rate of freezing of the standard isotope in rain $\left(\mathrm{P}_{r f r z}\right)$ and the mass mixing ratios of $\mathrm{H}_{2}^{16} \mathrm{O}$ and $\mathrm{HD}^{16} \mathrm{O}\left(r_{r}\right.$ and $r_{r}^{\prime}$, respectively):

$$
P_{r f r z}{ }^{\prime}=P_{r f r z} \frac{r_{r}^{\prime}}{r_{r}}
$$

On the other hand, the heavy isotopes are not uniformly distributed within individual particles of cloud ice, snow and graupel [see, e.g., Jouzel et al., 1975]. The molecular diffusivity in the solid phase is so small that one would expect the isotopic content of the ice to vary from layer to layer as the ice is deposited from vapor of varying isotopic content and during differing conditions (i.e., changing temperatures or supersaturations with respect to ice). In the present simulations, this effect is accounted for during deposition where vapor interacts with only the most recently deposited ice on the outer layer of the particle. However, this effect is neglected during sublimation because tracking the size and composition of differing layers within the ice would be 

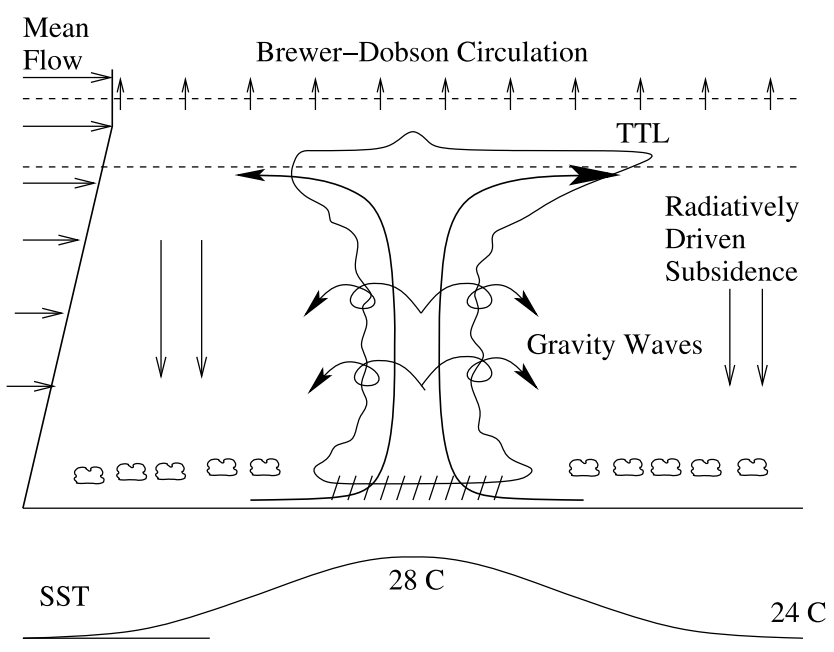

Figure 1. Sketch of idealized, equatorial Walker circulation. Note that there is no mean flow for the simulation NOADV. All other simulations use the mean zonal wind profile that resembles that in this sketch.

cumbersome. The vapor produced by sublimating ice is assumed to have the mean, mass-weighted isotopic composition of the ice particle. A sensitivity study described in section 7 attempts to characterize the errors that could be induced by neglecting the isotopic layering within ice particles during sublimation.

[17] In summary, the fractionation of the heavy isotopes during microphysical exchanges is included during the condensation of vapor onto cloud liquid, evaporation of cloud liquid and rain into vapor, and deposition of vapor onto ice and snow. It is assumed that no fractionation occurs during all other microphysical processes, including freezing, melting, and sublimation. The details of treatment of isotope exchange during microphysical processes are given in Appendix B.
[18] The treatment of fractionation during evaporation from the underlying ocean surface follows Bony et al. [2008], which includes the fractionation factor during evaporation as characterized by Merlivat and Jouzel [1979]. Ocean water is assumed to have no fractionation with respect to the standard, i.e., $\delta D=0, \delta^{18} O=0$.

\subsection{Simulation Design}

[19] The simulation framework employed in this paper provides a caricature of the equatorial Walker circulation within a two-dimensional domain (width $8192 \mathrm{~km}$, height $40 \mathrm{~km}$ ) over a sinusoidally varying, fixed sea surface temperature distribution with cyclic boundary conditions in the zonal $(x)$ direction. This framework has been used previously to explore the interactions of convection and radiation with large-scale circulations [Grabowski et al., 2000; Bretherton et al., 2006] and tropical climate sensitivity [Bretherton, 2007], and it is referred to here as a "mock Walker circulation" since its setting is much simpler than that of the real Walker circulation. To faithfully capture processes in the tropical tropopause layer, the setup is augmented with a Brewer-Dobson circulation, which is imposed as a largescale vertical velocity. As the mean vertical velocity of an anelastic model with cyclic boundary conditions is zero, advection by the large-scale vertical velocity associated with the Brewer-Dobson circulation is imposed as a source term as described by Khairoutdinov and Randall [2003]. A schematic of the simulation is given in Figure 1 and includes a caricature of the cloud field expected in this mock Walker circulation. The form of the Brewer-Dobson circulation is patterned after the observations of Yang et al. [2008] and has been applied in both stationary and seasonally varying form (Figure 2). The functional form of the vertical mass flux of the BrewerDobson circulation is given in Appendix A.

[20] The horizontally averaged horizontal winds are nudged to a specified profile on a $2 \mathrm{~h}$ time scale. While the simulation in section 3 uses a zero target wind profile, a sheared wind profile is used in the other simulations in this paper, with the zonal wind increasing linearly with height
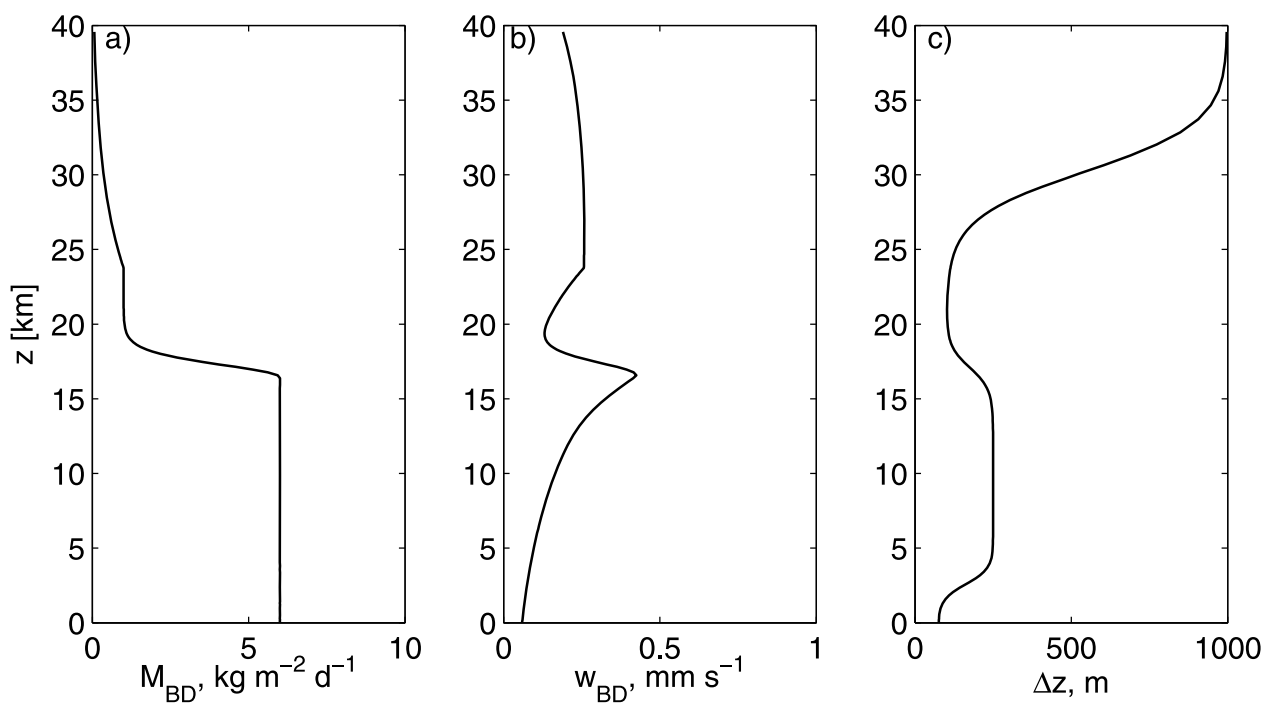

Figure 2. Sketch of (a) Brewer-Dobson circulation mass flux and (b) vertical velocity along with (c) the model's vertical grid spacing. 

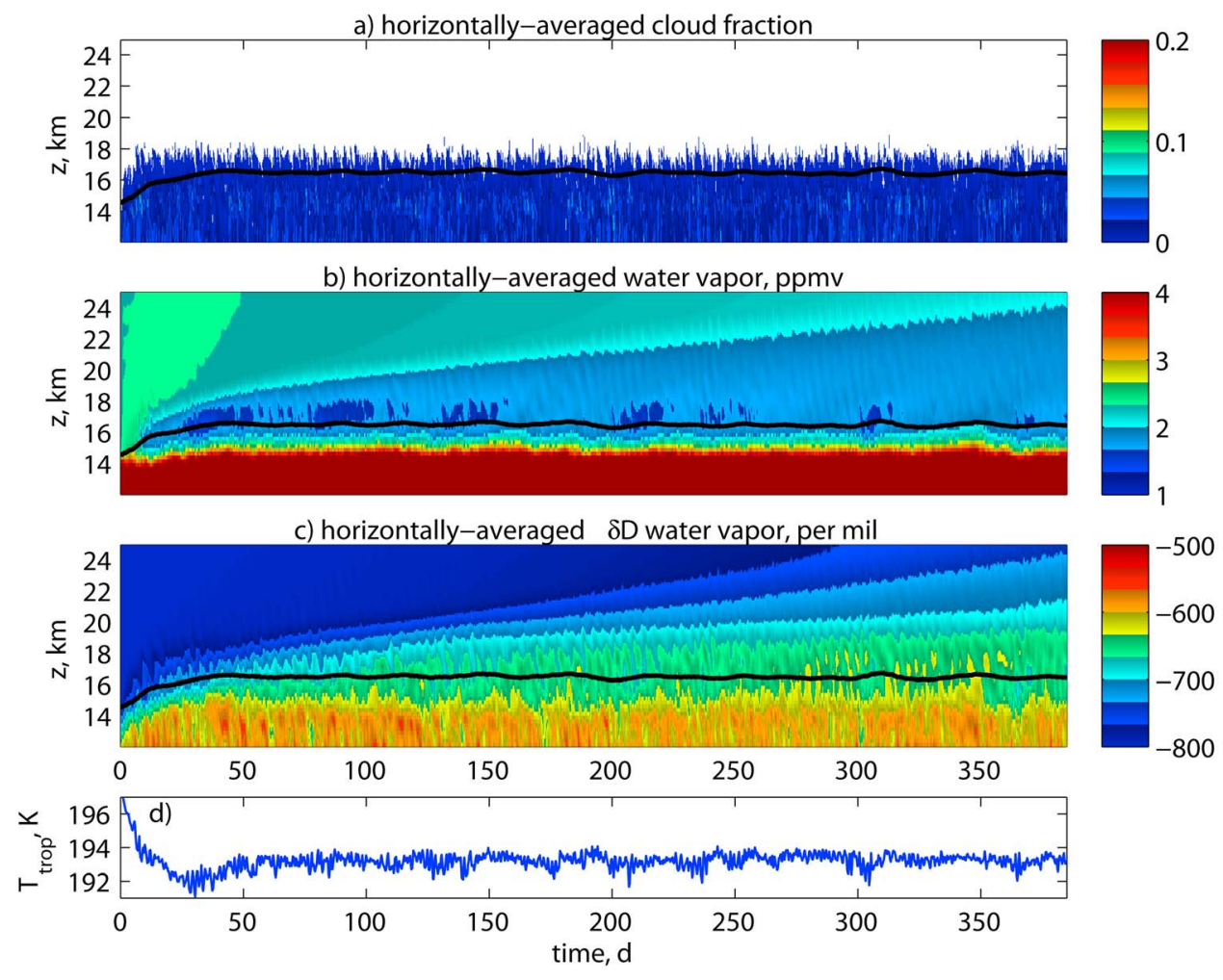

Figure 3. Evolution of horizontally averaged (a) cloud fraction, (b) water vapor mass mixing ratio, (c) $\delta \mathrm{D}$ of water vapor in the TTL, and (d) tropopause temperature in run NOADV.

from $0 \mathrm{~m} \mathrm{~s}^{-1}$ at the surface to $5 \mathrm{~m} \mathrm{~s}^{-1}$ at $14 \mathrm{~km}$ and uniform above that height, as sketched in Figure 1.

[21] A horizontal grid spacing of $2 \mathrm{~km}$ is used in all simulations in this paper, along with a variable vertical grid spacing of 75-300 m up to $25 \mathrm{~km}$ altitude with larger grid spacings above (see Figure 2c). A damping region, described by Khairoutdinov and Randall [2003], fills the top $30 \%$ of the domain to limit the reflection of gravity waves from the model top.

[22] No attempt has been made to represent chemical reactions in the lower stratosphere that affect water vapor (such as methane oxidation), so that the predictions of this model should be compared with observations that remove such effects [e.g., Kuang et al., 2003].

\section{Mock Walker Circulation With No Mean Flow Through the TTL}

[23] Here and in section 4, two simulations are described that differ in their mean zonal wind profile. In the present section, the simulation (called NOADV) has no mean zonal wind and no mean advection through the TTL, while section 4 describes a simulation with mean zonal flow through the TTL (called ADVECT). The mean advection through the TTL in ADVECT was mainly intended to evoke horizontal advection through the "cold trap" as per Holton and Gettelman [2001] and also has the effect of cycling air through the regions of the TTL above relatively colder and warmer SSTs. In the NOADV simulation, these regions of the TTL can remain relatively isolated from each other and allow one to see the processes at work in each region more distinctly.

[24] In the troposphere, each simulation settles into a statistically steady state in approximately $30-50$ days, as is typical in simulations of radiative-convective equilibrium [e.g., Tompkins and Craig, 1998]. In the tropical tropopause layer, the evolution is slower due to the Brewer-Dobson circulation and the long radiative relaxation time scale there. The time evolution of this run, in which the domain-mean zonal wind is nudged to zero at all heights, is seen in Figure 3. Here, the tropopause temperature (Figure 3d) adjusts in approximately 50 days, while the effect of the initial conditions on water vapor and its isotopic fractionation in the TTL ( 14-18.5 km [Fueglistaler et al., 2009]) are visible until about day 300.

[25] In the present simulation (NOADV) that lacks mean zonal advection through the TTL, a circulation develops in the troposphere that is symmetric about the warmest sea surface temperatures. This circulation, shown by contours of a mass stream function in Figure $4 \mathrm{a}$, is marked by deep convection over the warmest SSTs, while subsidence, shallow convection and boundary layer clouds predominate over the colder SSTs. The detrainment from deep convection mainly occurs between 9 and $14 \mathrm{~km}$, with only weak detrainment above that layer. The base of the TTL is roughly indicated in Figure $4 \mathrm{a}$ by the level of zero full sky radiative heating.

[26] Although high clouds occur over the whole domain, high cloud is more sporadic and in-cloud ice water contents are smaller over the colder SSTs than over the region of deep convection. In the lower troposphere, a shallow 

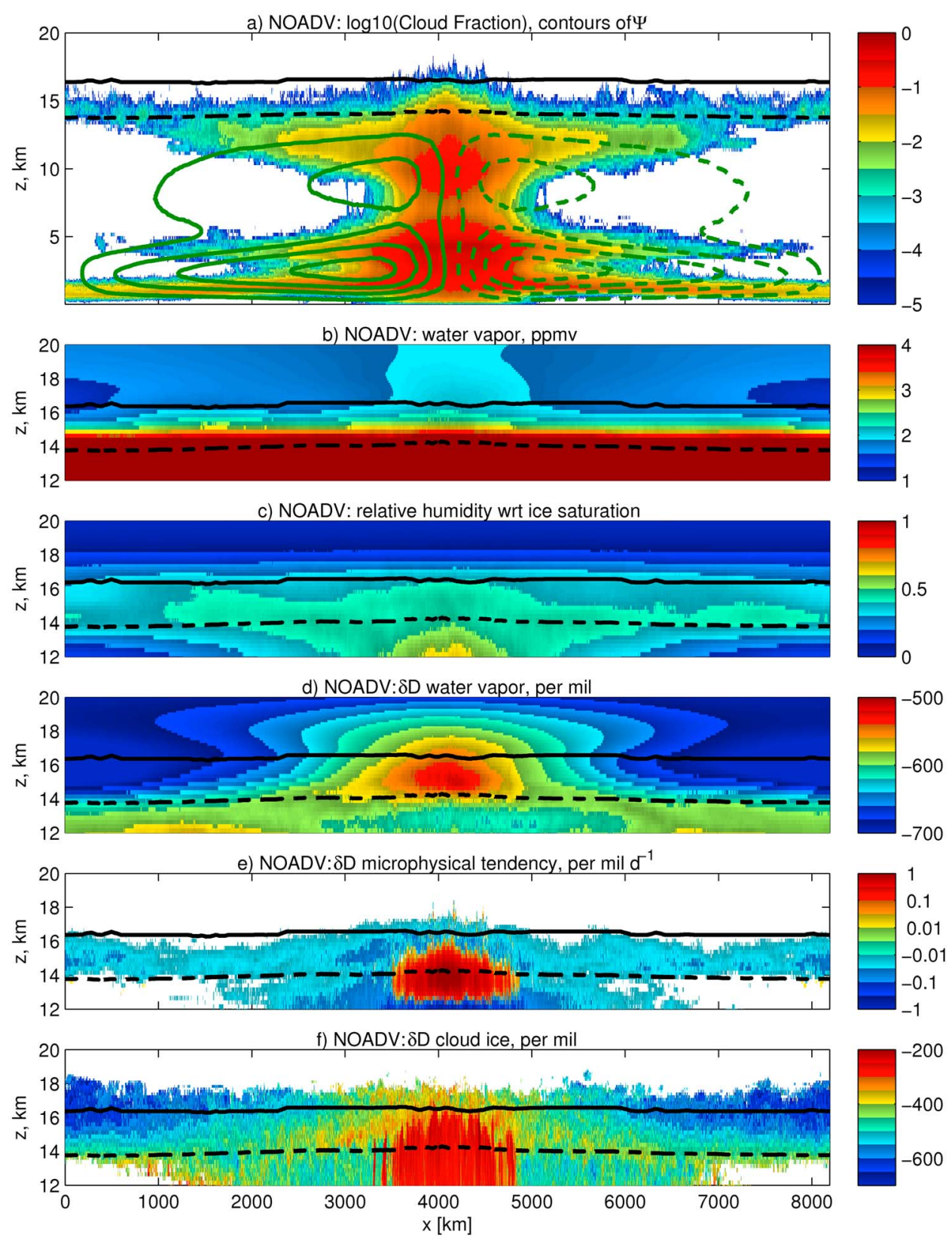

Figure 4. Time-averaged quantities from (a-f) NOADV and (g-l) ADVECT simulations. The mass stream function in Figures $4 \mathrm{a}$ and $4 \mathrm{~g}$ is computed from the time-averaged velocity field and reference density profile and is defined by Bretherton et al. [2006]. In each panel the thick black lines depict the location of the cold point tropopause (solid lines) and the level of zero full sky radiative heating (dashed lines). Both of these heights have been smoothed using a $100 \mathrm{~km}$ running average in the $x$ direction for clarity. Note that the isotopic ratios are computed from time-averaged mass mixing ratios and that the color scale limits for $\delta D$ of water vapor (Figures $4 \mathrm{~d}$ and $4 \mathrm{j}$ ) and cloud ice (Figures $4 \mathrm{f}$ and $4 \mathrm{l}$ ) differ substantially. Values of the microphysical source of $\delta D$ between -0.01 and 0.01 per mil d $\mathrm{d}^{-1}$ have not been plotted in Figures $4 \mathrm{e}$ and $4 \mathrm{k}$ to emphasize the regions of significant sources and sinks of $\delta D$.

circulation returns air from the convective region above the boundary layer. The subsidence associated with the deep and shallow circulations together maintains an inversion that caps boundary layer cloud over the colder SSTs. The combination of the mean subsidence with the lack of synoptic variability causes the free tropospheric air over the colder SSTs to be extremely dry. Such dry air is sometimes observed in the subtropical free troposphere, as during the VOCALS experiment [Bretherton et al., 2010].

[27] The ease with which gravity waves propagate in twodimensional simulations (with no amplitude falloff with 

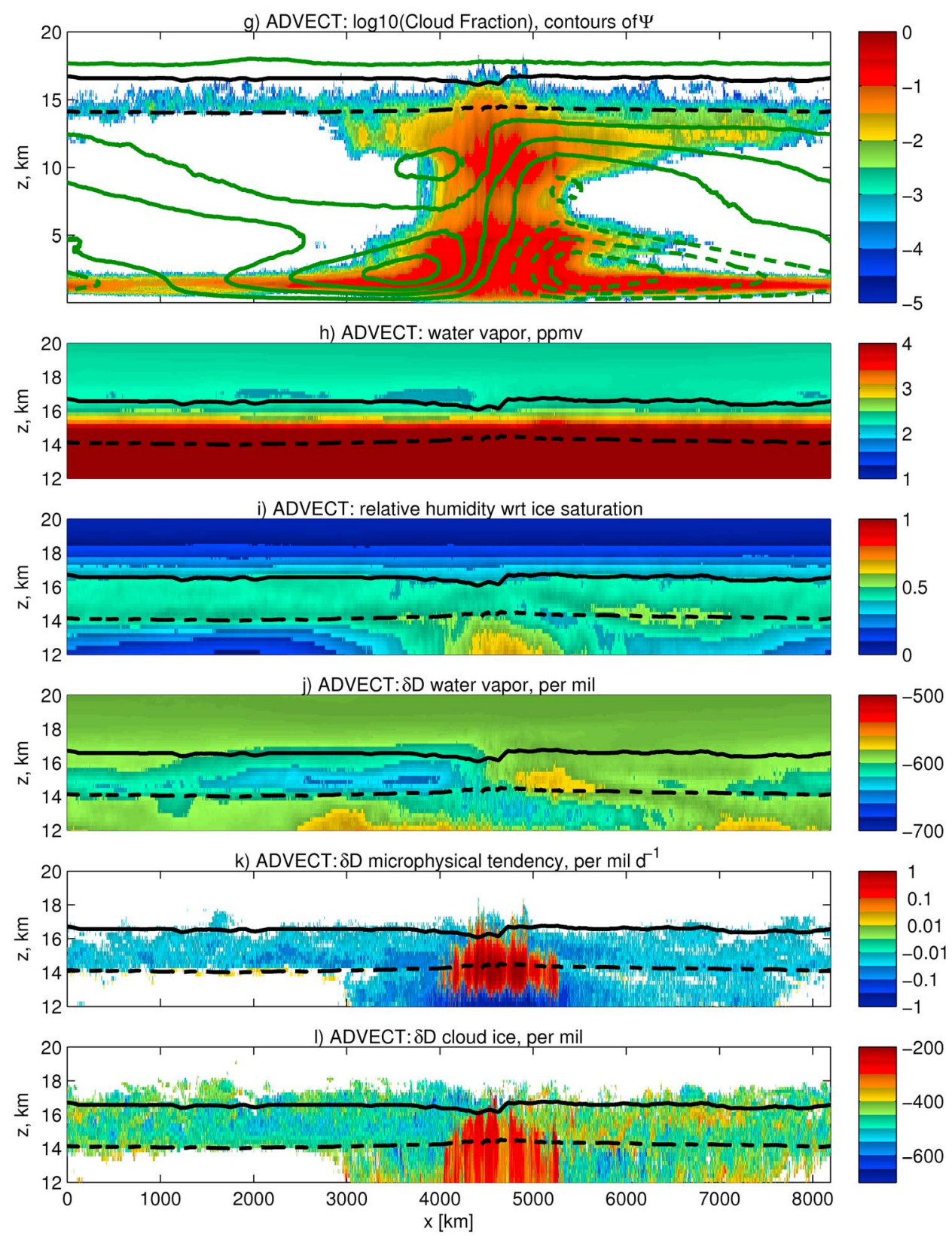

Figure 4. (continued)

range due to dimensionality as in three dimensions [see, e.g., Zeng et al., 2007, Appendix]) led to a resonant gravity wave with a period of approximately 2 days in the findings of Grabowski et al. [2000]. On alternate days, the vertical motion associated with the gravity wave (itself generated by the convective heating) would enhance and suppress deep convection and rainfall over the warmest SSTs. In our larger domains, the corresponding wave would have a period of approximately 4 days. Variability is found on this time scale in the domain-averaged precipitation (Figure 5a). The introduction of a domain-mean wind profile with shear and mean advection through the TTL (discussed in section 4) leads to slightly less variability on this time scale.
[28] Precipitation is concentrated in the center of the domain over the warmest SSTs, with peak time-averaged precipitation rates around $35 \mathrm{~mm} \mathrm{~d}^{-1}$ (Figure $5 b$ ). Roughly a quarter of the domain experiences precipitation at a rate greater than $1 \mathrm{~mm} \mathrm{~d}^{-1}$. The isotopic fractionation of the precipitation in the center of the convective region, $\delta D \sim$ $-70 \%$ is more depleted than the bulk of the observations presented by Bony et al. [2008]. The range of $\delta D$ in these simulations, however, is similar to those of the single column model simulations in that work. The deuterium excess values $d$ are between 10 and 15 in the convective region, in alignment with observations in the tropics [e.g., Bony et al., 2008], although somewhat higher deuterium excess values are present in regions of weak precipitation. The air above 

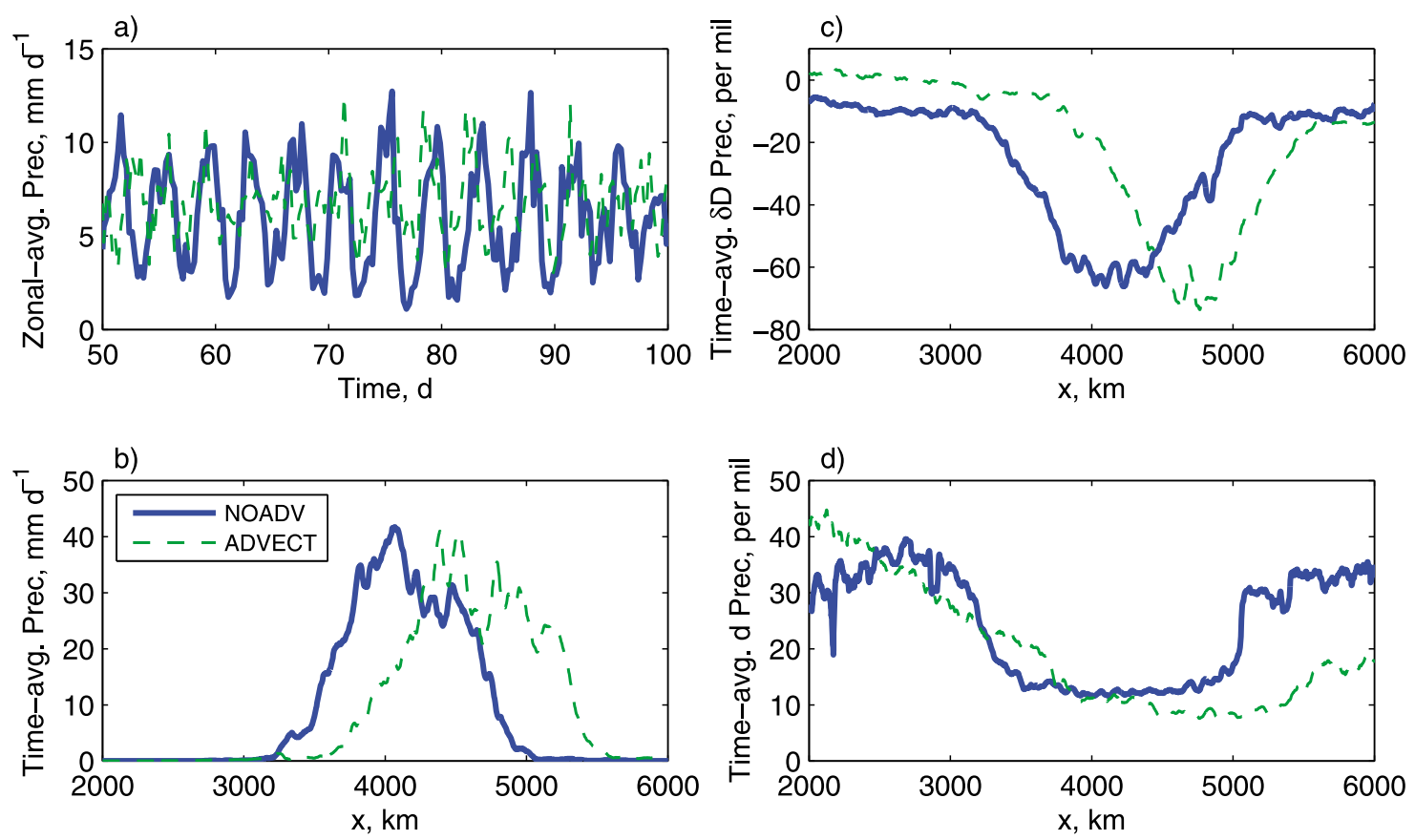

Figure 5. (a) Time series of domain-averaged, $6 \mathrm{~h}$ averaged precipitation rate from NOADV and ADVECT runs. Spatial variation of time-averaged (b) precipitation, (c) $\delta D$ of precipitation, and (d) deuterium excess $d$ of precipitation. The data in Figures $5 \mathrm{~b}-5 \mathrm{~d}$ have been smoothed with a $50 \mathrm{~km}$ running average in $x$. The large values of deuterium excess in regions of weak precipitation are likely related to large values of deuterium excess (characteristic of the upper troposphere) that are present above the boundary layer in the subsiding regions of the mock Walker circulation.

the boundary layer in these regions is also marked by large values of deuterium excess and is associated with the subsidence of this air from the upper troposphere (not shown). Departures of the Rayleigh curve in $\delta D-\delta^{18} O$ space from the slope of eight implied by the definition of deuterium excess $\left(d=\delta D-8 \delta^{18} O\right)$ causes air in the upper troposphere over the convective region to have a high deuterium excess $(d \sim 150-200)$. This air subsequently detrains from the convective region and subsides to the trade inversion in the subsiding region, where it mixes with boundary layer air.

[29] In the tropical tropopause layer, the region above the warmest SSTs is relatively moister and has more cloud than that above subsidence regions (Figures $4 a-4 c$ ). The vapor in the TTL above the convective region is enriched relative to the vapor below the base of the TTL, while the vapor in the TTL above the subsidence regions is isotopically lighter than the underlying vapor (Figure $4 \mathrm{~d}$ ). This vertical structure of $\delta D$ resembles that seen in in situ observations of CR-AVE by Sayres et al. [2010], who also found a minimum of $\delta D$ near the base of the TTL. Since eddy motions acting across this gradient of $\delta \mathrm{D}$ at the base of the TTL in the convective region would tend to lighten the vapor there, this suggests that microphysical processes balance these eddy processes by enriching the vapor in the TTL. Figure $4 \mathrm{e}$ shows that this is indeed the case, with microphysical sources of $\delta \mathrm{D}$ enriching the vapor at the base of the TTL. While the budget of $\delta \mathrm{D}$ will not necessarily be closed (separate budgets for the total mass of $\mathrm{H}_{2}^{16} \mathrm{O}$ and
$\mathrm{HD}^{16} \mathrm{O}$ are), computing the contributions to fractionation directly can yield some insight. The contribution of microphysical processes, for example, can be computed as:

$$
\left.\frac{\partial \delta D}{\partial t}\right|_{\text {micro }}=\frac{M_{\text {rat }}}{V_{S M O W}}\left[\left.\frac{1}{r_{v}} \frac{\partial r_{v}^{\prime}}{\partial t}\right|_{\text {micro }}-\left.\frac{r_{v}^{\prime}}{r_{v}^{2}} \frac{\partial r_{v}}{\partial t}\right|_{\text {micro }}\right]
$$

where $V_{S M O W}$ is the standard ratio and $M_{\text {rat }}$ is the ratio of molecular masses which converts the mass ratio $r_{v}^{\prime} / r_{v}$ into a ratio of the isotope abundances. Note that (3) is computed from the definition of $\delta D$ using the quotient rule. Near the base of the TTL, at approximately $13 \mathrm{~km}$, the sign of the microphysical tendency of $\delta D$ changes, and over a region about a thousand kilometers wide and up to $3 \mathrm{~km}$ deep, the vapor is enriched by microphysical processes, presumably the sublimation of enriched ice carried from lower in the troposphere by convection.

[30] As the time-averaged temperature is relatively uniform in the zonal direction, both the specific and relative humidity in the TTL fall off away from the convective region. Cloud is present in the TTL above the subsidence regions (Figure 4a). However, that cloud tends to have small in-cloud liquid water contents and is associated with the cloud ice whose HDO fractionations (Figure 4f) are indicative of in situ cloud formation, as opposed to detrainment of ice from the convective region. As seen in Figure $4 \mathrm{e}$, microphysical processes act to deplete the vapor in these regions. The mass stream function suggests that the air in this region is relatively isolated from the time-mean tropo- 

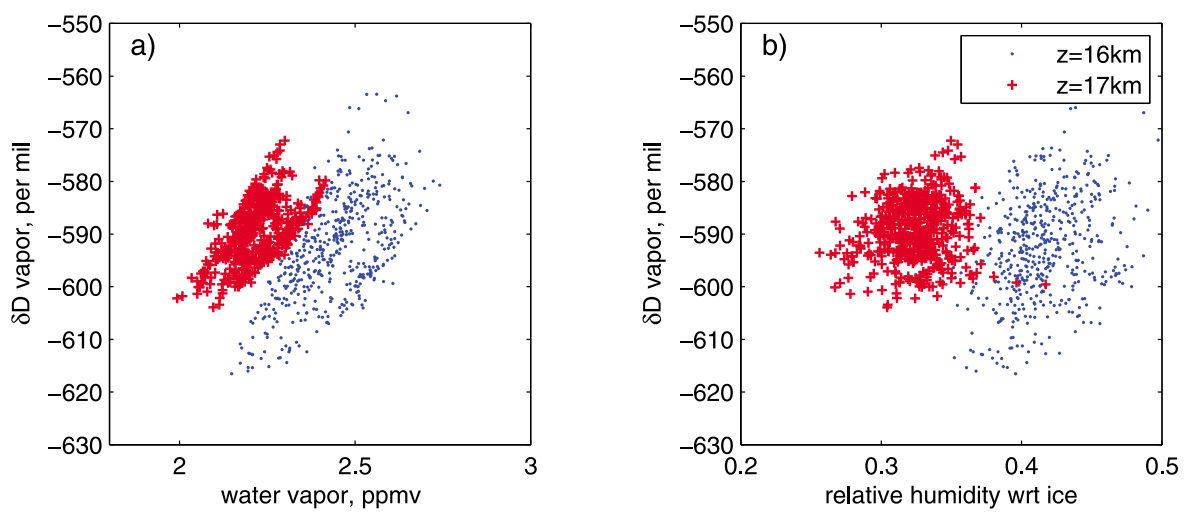

Figure 6. Scatterplot of $\delta \mathrm{D}$ against (a) water vapor amount and (b) relative humidity with respect to ice saturation at two heights: $\mathrm{z}=16,17 \mathrm{~km}$. All quantities are horizontal and $6 \mathrm{~h}$ averages from the times following day 70 of simulation ADVECT. The fractionations are computed from the averaged mass mixing ratios of $\mathrm{H}_{2}^{16} \mathrm{O}$ and $\mathrm{HD}^{16} \mathrm{O}$ in water vapor.

spheric circulation. Its isolation from the moister air atop the convective region allows it to become much drier and more depleted than the air there. The Brewer-Dobson circulation carries these disparate air masses into the upper part of the TTL and into the lower stratosphere.

[31] As the subtropical jets, equatorial wave activity and synoptic activity act to limit the isolation of air masses in the TTL in the real tropics, this scenario - while instructive - is probably unrealistic. However, it provides a starting point for exploring the mechanisms that fix the isotopic content of water vapor in the TTL. In the following, a zonal flow with mean advection through the TTL is introduced in the mock Walker circulation. This carries air from the subsiding region into the convective region in both the troposphere and in the TTL and leads to variability of $\delta D$ in the TTL that is more in line with observations.

\section{Mock Walker Circulation With Mean Advection Through the TTL}

[32] In the present section, a simulation (termed ADVECT) has been performed over the same zonally varying sea surface temperature distribution and with the same, steady BrewerDobson circulation as above. However, instead of relaxing the horizontally averaged winds to zero, here the mean zonal wind is relaxed on a $2 \mathrm{~h}$ time scale to a sheared profile with mean advection through the TTL that varies linearly with height from zero at the surface to $5 \mathrm{~m} \mathrm{~s}^{-1}$ at $14 \mathrm{~km}$ and is
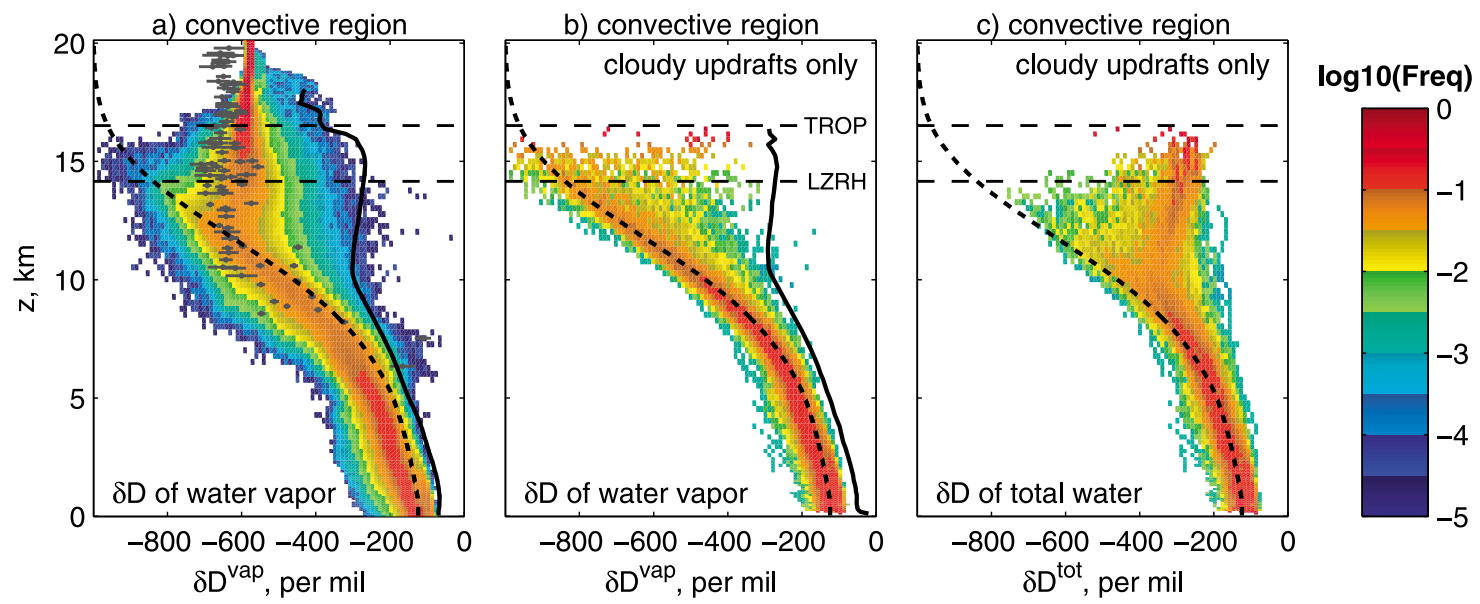

Figure 7. Frequency distribution of $\delta \mathrm{D}$ for a column of air in the core of the convective region in (a) water vapor, (b) water vapor in cloudy updrafts $\left(w>1 \mathrm{~m} \mathrm{~s}^{-1}\right)$, and (c) total water in cloudy updrafts. The short-dashed line in each plot is a Rayleigh curve whose surface properties are the mean properties of buoyant updrafts at $500 \mathrm{~m}$ altitude. The solid lines in Figures $7 \mathrm{a}$ and $7 \mathrm{~b}$ show the average $\delta D$ of all condensate at each level for all points and for cloudy updrafts, respectively. Dashed lines in the upper troposphere depict the mean height of the cold point tropopause (TROP) and level of zero full sky radiative heating (LZRH). The gray points and lines represent the ATMOS observations of $\delta D$ in water vapor and their uncertainties [Kuang et al., 2003]. Note that the ATMOS data has been adjusted to remove the effects of methane oxidation. 

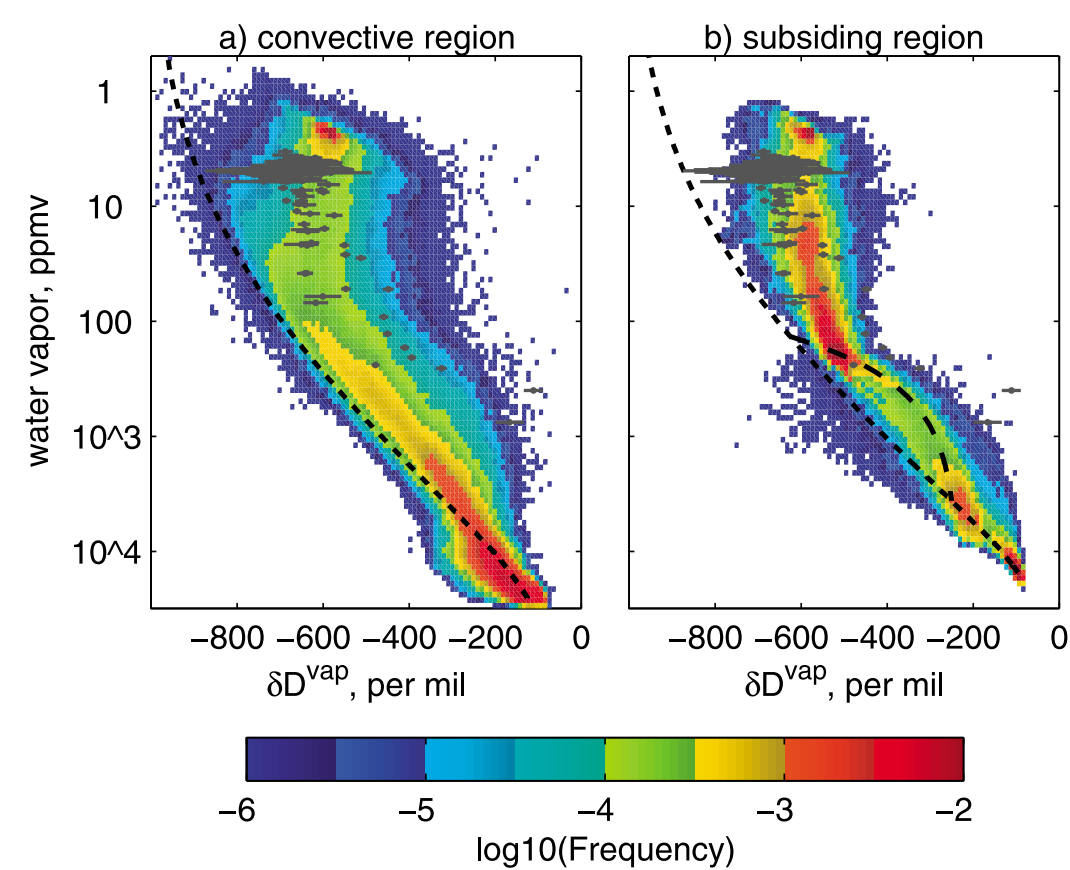

Figure 8. Joint frequency distribution of $\delta D$ (per mil) and $\mathrm{H}_{2}^{16} \mathrm{O}$ (ppmv) for (a) the convective region and (b) the subsiding region of ADVECT. The Rayleigh line (short-dashed line) and ATMOS data (grey points) are shown as in Figure 7a above. In Figure $8 \mathrm{~b}$ the long-dashed line is a mixing curve between conditions on the Rayleigh line at $\delta D=-250$ and $\delta D=-625$.

uniform above that height. This wind affects both the structure of the tropospheric circulation and the circulation of air in the TTL. In particular, parcels carried by the mean zonal wind of $5 \mathrm{~m} \mathrm{~s}^{-1}$ in the TTL would traverse the periodic, $8192 \mathrm{~km}$ domain in approximately 20 days. The simulation ADVECT was initialized from a previous 400 day simulation with an identical framework except for a small change to the microphysics that has little impact on the TTL. Results are only shown following a further 70 days of simulation during ADVECT.

[33] The mean zonal flow leads to an asymmetric circulation with detrainment predominantly downwind of the convective region (Figure $4 \mathrm{~g}$ ). The peak of surface precipitation (Figure $5 \mathrm{~b}$ ) and the cloud associated with deep convection (Figure 4g) are shifted downstream of the SST peak around $\mathrm{x}=4100 \mathrm{~km}$. Larger upper tropospheric cloud fractions are found downwind of the convective region, as are a deeper circulation and deeper cloud tops in the lower stratosphere. The smallest upper tropospheric cloud fractions occur approximately $2000 \mathrm{~km}$ upwind of the convective region.

[34] The zonal flow through the TTL leads to humidity and isotopic fractionations there that are much more homogeneous than was seen in the absence of this shear and mean flow. The fractionations in the TTL range from $\sim-580 \%$ to $-630 \%$, which are within the observational uncertainty of the remote measurements of Kuang et al. [2003]. The most enriched vapor in the TTL lies downwind of the convective region near the base of the TTL (Figure 4j). As in the simulation without the mean wind and shear, microphysical sources tend to enrich the vapor at the base of the TTL over the convection (Figure 4k), so that this vapor is likely enriched by the sublimation of relatively richer ice lofted by the convection before being advected downwind of the convective region. The most depleted vapor in the TTL lies upwind of the convective region, which is also the location of the driest air. Figure 6 shows scatterplots of horizontally averaged properties at two heights that straddle the coldpoint tropopause: 16 and $17 \mathrm{~km}$. As seen in Figure 6, the internal variability in horizontally averaged $\delta D$ of water vapor near the tropopause in this steadily forced simulation is correlated with water vapor amount and, to a lesser extent, with relative humidity. Although the air is relatively drier above the cold-point tropopause than it is below, the mean fractionation is relatively unchanged.

[35] The water vapor content of air near and above the tropopause is low in these runs compared to observations. Steinwagner et al. [2010], for example, show tropical average values that vary between about 3-4.5 ppmv during the seasonal cycle. As shown in Figure 6, the values near the tropopause in this simulation are in the range 2-3 ppmv. Possible reasons for the relatively dry lower stratosphere in these simulations include the neglect of supersaturation with respect to ice, ice fallspeed parameterizations that do not account for the small characteristic particle size of thin cirrus clouds near the tropopause, and strong gravity waves resulting either from vigorous convection or from the weaker decay of gravity waves with distance in two-dimensional than in threedimensional simulations. The first two of these mechanisms will be tested using sensitivity studies in section 7 below.

\section{Distribution of Isotopic Ratios Through the Atmospheric Column}

[36] As predicted by Rayleigh theory, ascending surface parcels become more depleted as the heavy water $\left(\mathrm{HD}^{16} \mathrm{O}\right.$ and $\mathrm{H}_{2}^{18} \mathrm{O}$ ) are removed preferentially through condensation 

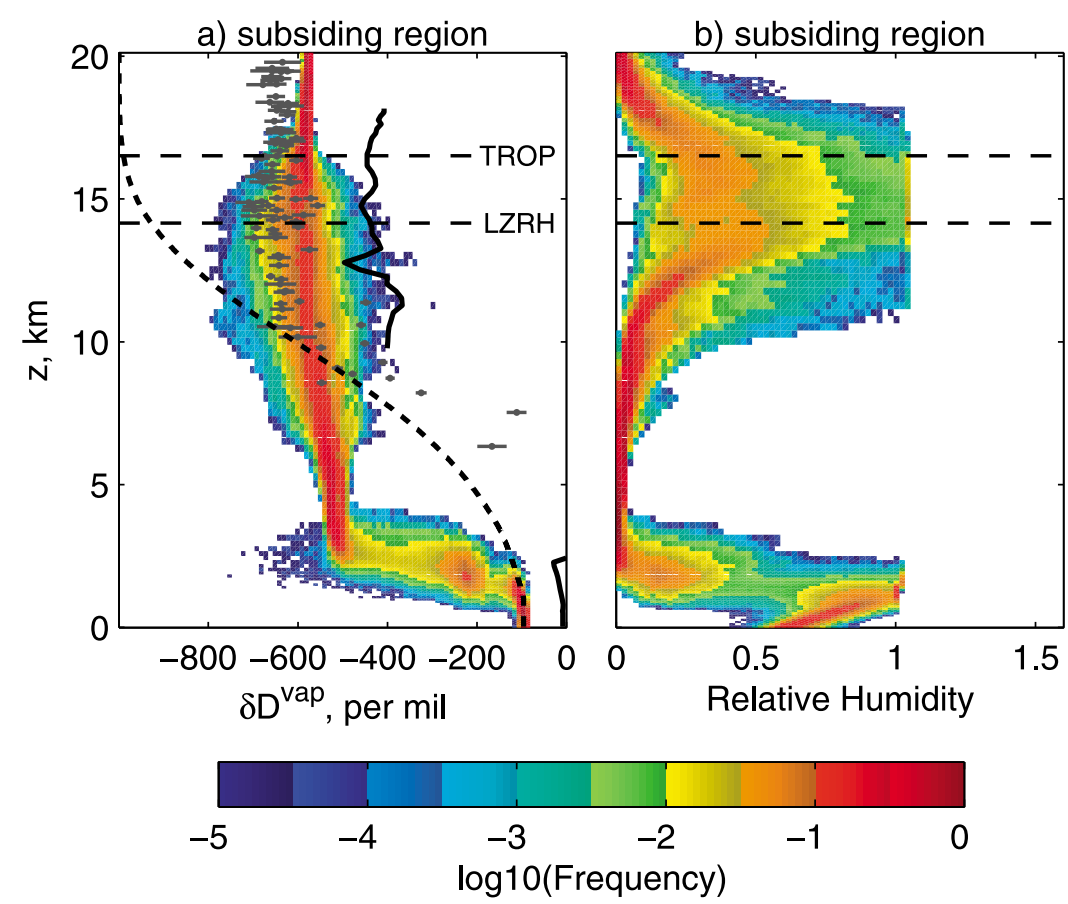

Figure 9. Frequency distribution of (a) $\delta \mathrm{D}$ in water vapor and (b) relative humidity (with respect to liquid saturation for $T>0^{\circ} \mathrm{C}$ and ice below) as a function of height for a column of air within the subsiding region. Rayleigh curve (short-dashed line), $\delta D$ of condensate (solid line), tropopause height (long-dashed line), LZRH (long-dashed line), and ATMOS data (grey points) are shown as in Figure 7.

and precipitation as those parcels rise and cool adiabatically. In the Rayleigh model, condensate is removed immediately so that the isotopic fractionation of total water is identical to that of water vapor. Single column models that include isotopic fractionation [e.g., Bony et al., 2008] relax this assumption, so that some condensate remains with the ascending parcels. These models also permit the modification of the fractionation of the base sounding through evaporation of precipitation and sometimes include multiple plumes or parcels to represent the variability in plume properties and evolution. In the present cloud resolving model simulations, the plumes and their interactions with their environment are simulated explicitly. Except for radiation (which is computed using an independent column approximation), the parameterizations employed are local in nature and represent the effects of unresolved scales through the subgrid-scale and microphysics parameterizations. While these simulations are limited in resolution and microphysical complexity by their expense, the variability of thermodynamic and microphysical properties is more fully represented here than in more simplified models.

[37] Figure 7a shows the frequency of occurrence of $\delta D$ in vapor $\left(\delta D^{v a p}\right)$ at each height and how this varies as a function of height for a $200 \mathrm{~km}$ column of air in the center of the convective region. The distributions, taken from day 70-200 of ADVECT, largely follow the trend of the Rayleigh curve (short-dashed line) with much scatter. Note that the properties of the parcel used to compute the Rayleigh curve are those of the average buoyant updraft at $500 \mathrm{~m}$ altitude in this region. In the lower troposphere, the air is generally more depleted than if the air had ascended in a Rayleigh process (i.e., with zero entrainment and complete removal of condensate). In the upper troposphere, at about $12 \mathrm{~km}$, the distribution departs from the relationship between water vapor and $\delta D$ represented by the Rayleigh curve, with a broad distribution of $\delta D$ that narrows to nearly a single value just above the tropopause that is nearly constant above $19 \mathrm{~km}$. The observations of $\delta D$ in water vapor from ATMOS [Kuang et al., 2003] have a similar vertical structure to the present simulation, lying close to - but slightly more depleted than - the mode of the $\delta D$ distribution from ADVECT. The fractionation of condensate (shown by solid lines in Figures $7 \mathrm{a}$ and $7 \mathrm{~b}$ ) is roughly uniform in the vertical above about $10 \mathrm{~km}$, falling off only within about $500 \mathrm{~m}$ of the cold point tropopause.

[38] As seen in Figure 7b, the Rayleigh curve accurately describes the fractionation of water vapor in cloudy updrafts (defined by cloud condensate greater than $10^{-6} \mathrm{~kg} \mathrm{~kg}^{-1}$ and vertical velocity exceeding $1 \mathrm{~m} \mathrm{~s}^{-1}$ ). Departures from the Rayleigh curve in the upper troposphere are mainly richer in $\mathrm{HD}^{16} \mathrm{O}$. Total water in cloudy updrafts that reach the upper troposphere (Figure 7c) is much richer than the Rayleigh curve due to condensate (both cloud and precipitation) that has been carried from the lower and mid troposphere. The divergence of the total water distribution from the Rayleigh curve depends on the precipitation efficiency, as well as on the entrainment and mixing between convective plumes and their environment. The Rayleigh curve expresses the limit of zero entrainment and complete precipitation removal (a precipitation efficiency of 1) [see, e.g., Bony et al., 2008]. Note that a few updrafts reach into the TTL with values of $\delta D$ near $-250 \%$, which are close to those at the surface $(\delta D \sim-200$ to $-90 \%)$. While this might suggest that there are a few weakly entraining plumes that reach into the 

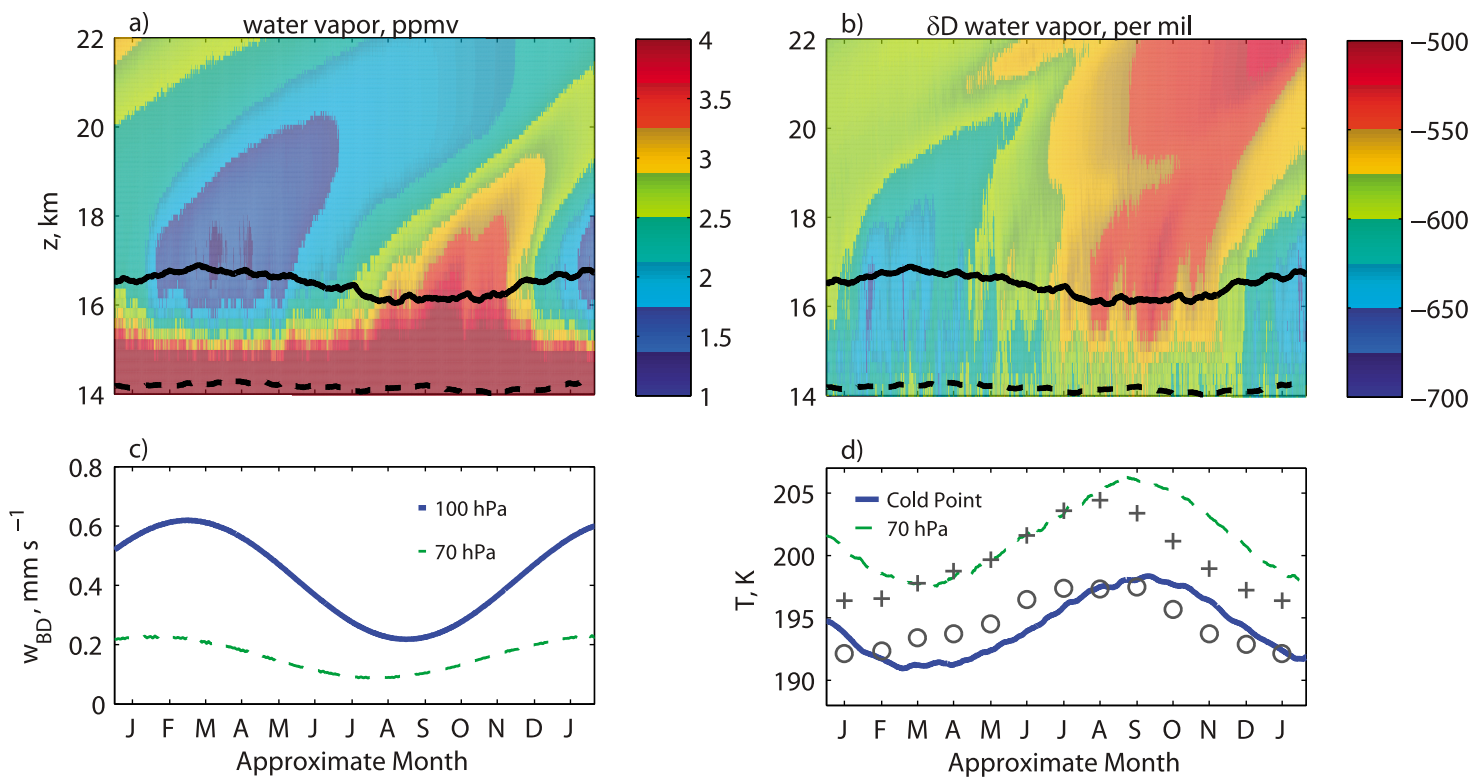

Figure 10. (a, b) Seasonal cycle of water vapor mass mixing ratio and $\delta \mathrm{D}$ in the TTL, along with time series of (c) the magnitude of the Brewer-Dobson circulation at 70 and $100 \mathrm{hPa}$ and (d) the temperatures at $70 \mathrm{hPa}$ and the cold point tropopause. Monthly averaged SHADOZ temperature data circles for tropopause, and pluses for $70 \mathrm{hPa}$ ) from 1998-2009, provided by Qiong Yang, are shown as a reference for the annual cycle of the temperature. The months on the time axis are approximate and correspond to the seasonal cycle of the imposed Brewer-Dobson circulation. The heights of the tropopause and the level of zero full sky radiative heating are shown as in Figure 4.

TTL, $\delta D$ does not mix linearly [see, e.g., Dessler and Sherwood, 2003] so that the $\delta D$ an enriched parcel with total water characteristic of the lower or mid troposphere would be little affected by mixing with very depleted vapor in the TTL because of the low water vapor amounts there.

[39] The joint frequency distribution of $\delta D$ and water vapor in the convective region (Figure 8a) has two peaks: one in the lower troposphere and another reflecting the levels of $\delta D$ and $\mathrm{H}_{2}^{16} \mathrm{O}$ in the lower stratosphere. In between, there is a broad distribution of $\delta D$ for a given level of water vapor that is generally richer than the Rayleigh curve. The upper tropospheric values depart significantly from the Rayleigh curve for water vapor below about 50 ppmv. The ATMOS data overlap those from ADVECT for water vapor below 100 ppmv, though the lower stratosphere in ADVECT is somewhat richer in $\delta D$ and drier than the ATMOS data. In this region, the data from ADVECT scatter above and below the lower stratospheric values in both $\delta D$ and water vapor. The variability in these quantities decreases as the air ascends through the TTL. Mixing is likely responsible for much of the reduction in variability of $\delta D$ with height in the TTL. As suggested by Dessler and Sherwood [2003] and Kuang et al. [2003], mixing of parcels with disparate values of $\delta D$ will be dictated largely by the parcel with the larger water vapor content and could lead to a relatively uniform profile of $\delta D$ with height in the TTL despite the decrease in water vapor amount with height. A second-likely smaller-effect that could play some role in reducing the variability of $\delta D$ in the TTL is the sublimation of ice into highly depleted updrafts as they subsequently sink and warm adiabatically or as they mix with the environment. The potential for this effect is seen in the contrast between the $\delta D$ of water vapor and total water in cloudy updrafts in the TTL in Figures 7b and 7c. Note that Dessler and Sherwood [2003] included this effect in their conceptual model for $\mathrm{HD}^{16} \mathrm{O}$ in the TTL.

[40] In the subsidence region, the boundary layer properties (and, in particular, those of cloudy updrafts) closely follow the Rayleigh line, as shown in Figure 9a. (Note that the Rayleigh curve is defined using a parcel whose properties are those of an average buoyant updraft at $500 \mathrm{~m}$ height in this region.) Above the boundary layer, the value of $\delta D$ is roughly preserved by the subsiding motions that balance radiative cooling in this region. The joint distribution of $\delta D$ and water vapor for the subsiding region in Figure $8 \mathrm{~b}$ shows that the differences in the $\delta D$ distributions with height between the convective and subsiding region result mainly from the relative dryness of the air in the subsiding region. The distributions are similar for water vapor less than $100 \mathrm{ppmv}$, though there is less variability of $\delta D$ for a given level of water vapor in the subsiding region. A notable departure between the distributions is depicted by the long-dashed line in the subsiding region plot. This is a mixing line for two parcels on the Rayleigh line at $\delta D=$ -250 and $-625 \%$ that have been chosen to pass through the two peaks in Figure $8 \mathrm{~b}$ at $\delta D \sim-200$ and $-500 \%$. The correspondence of this mixing line with the ridge in the joint $\delta D$-water vapor distribution in the subsiding region suggests that mixing is the dominant process fixing $\delta D$ for this range of vapor and fractionation. The role of mixing in fixing the isotopic composition of water vapor in the subtropical free troposphere has also been emphasized by Galewsky and Hurley [2010] based on work with an advection-condensation model. The observations of water 


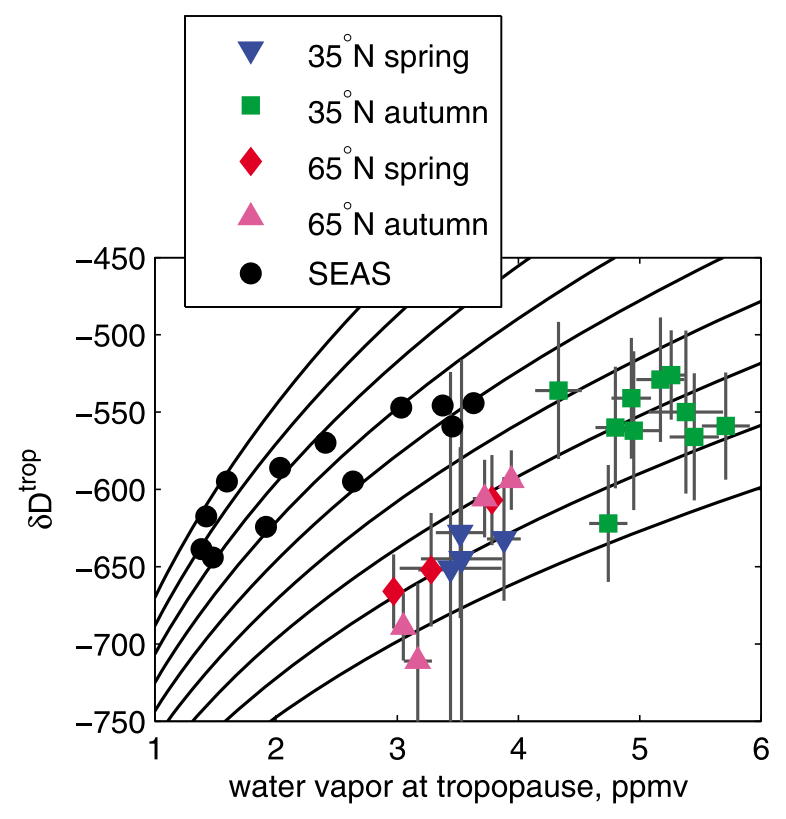

Figure 11. Comparison of 30 day averages of water vapor and $\delta D$ at the tropopause from SEAS with observational estimates of $\mathrm{H}_{2}^{16} \mathrm{O}$ and $\delta D$ at entry to the stratosphere from Notholt et al. [2010]. The latitude and season of each set of observations is indicated in the legend, and $1 \sigma$ error bars are shown for each estimate. The black lines are Rayleigh curves started from a variety of initial isotopic ratios at the mean level where the vapor amount is 5 ppmv. This image is patterned after Figure 2c of Notholt et al. [2010].

vapor and $\delta D$ on Mauna Kea, Hawaii, by Galewsky et al. [2007] also suggest the importance of mixing in fixing $\delta D$ near the trade inversion in the subtropics. In the present simulations, the frequency distribution of $\delta D$ with height in Figure 9a shows the mixing of depleted air subsiding from the upper troposphere with richer boundary layer air across the trade inversion between about 2 and $4 \mathrm{~km}$ and leads to a wide distribution of $\delta D$ at these altitudes (between about -150 and $-600 \%$ ). The complete absence of deep convection in the subsiding regions in these simulations leads to extremely dry conditions in air above the boundary layer, with a tight distribution of low relative humidities $(<5 \%)$ between 4 and $6 \mathrm{~km}$ (Figure 9b). However, these simulations do suggest that highly depleted air, characteristic of the tropical upper troposphere might be found in locations beneath the descending branches of the Walker and Hadley circulations.

\section{Seasonal Cycle of Isotopic Composition of Water Vapor in TTL}

[41] Observations by Nassar et al. [2007] and Payne et al. [2007] suggested possible presence of a seasonal cycle in $\delta D$ of water vapor in the TTL and lower stratosphere. At an advanced stage of our study, observations by Notholt et al. [2010] and Steinwagner et al. [2010] have further confirmed and quantified this seasonal cycle. In the present, idealized simulations, seasonal variations of $\delta D$ in the TTL and lower stratosphere have been explored by modulating the Brewer-
Dobson circulation following the observationally derived seasonal cycle of Yang et al. [2008] (see Appendix A for a detailed formulation). No variability in surface conditions or solar forcing was imposed in these simulations, so that the Brewer-Dobson circulation is the only unsteady external forcing applied in this simulation. Seasonal variations in ozone were also neglected. These were shown to affect the amplitude and phase of the annual cycle of tropopause temperature by Folkins et al. [2006] and Chae and Sherwood [2007]. This simulation (called SEAS) was initialized from day 400 of an earlier simulation and run for another 400 days. The water vapor amount, $\delta D$ fractionation, $70 \mathrm{hPa}$ temperature, cold-point tropopause temperature, and the BrewerDobson vertical velocity at 70 and $100 \mathrm{hPa}$ are shown in Figure 10. The temperatures show reasonable agreement with the SHADOZ (Southern Hemisphere Additional Ozonesondes) data [Thompson et al., 2003], although the average $70 \mathrm{hPa}$ temperature in the simulations is warmer than the observations. The minimum temperatures in the simulations occur in March, when the imposed Brewer-Dobson circulation reaches its maximum strength. Variations in the phase of the seasonal cycle in $\delta D$ among the observations complicate the assessment of the phase of the $\delta D$ seasonal cycle in the present simulation. The time-height plots of water vapor and $\delta D$ in the lower stratosphere (Figures 10a and 10b) have some of the "tape recorder" structure suggested by Mote et al. [1995] and seen clearly for $\delta D$ by Steinwagner et al. [2010]. The amplitude of the signal tends to fall off with height slightly faster than that observed by Steinwagner et al. [2010], who attributed the decay to mixing processes in the stratosphere. Here, these mixing processes are likely related to breaking gravity waves or numerical diffusion related to the monotonic advection scheme used in the cloud-resolving model.

[42] Notholt et al. [2010] used observations from the midlatitudes and the budgets for total hydrogen and total deuterium in the stratosphere to estimate the stratospheric entry values for water vapor and $\delta D$. These estimates are shown in Figure 11 along with 30 day averages of water vapor and $\delta D$ at the tropopause from the simulation with a seasonally varying Brewer-Dobson circulation (SEAS). Note that Figure 11 has been patterned after Figure 2c of Notholt et al. [2010]. The seasonal cycle in water vapor at the TTL in SEAS varies from $\sim 1.3$ to $\sim 3.7 \mathrm{ppmv}$, based on 30 day average values. There is a similar seasonal cycle in $\delta D$ from $\sim-650 \%$ in April to $\sim-540 \%$ in October. The range of this seasonal cycle in $\delta D$ is somewhat narrower than that observed by Notholt et al. [2010] but close to the observations of Steinwagner et al. [2010]. The low vertical resolution of the $\mathrm{HD}^{16} \mathrm{O}$ retrieval in MIPAS $(\sim 6 \mathrm{~km})$ may have diminished the amplitude of the seasonal cycle from Steinwagner et al. [2010] relative to that of Notholt et al. [2010], whose instrument had a vertical resolution on the order of $1 \mathrm{~km}$. As noted above, the water vapor amounts are smaller in the present simulations than in the observations, though the amplitude of the seasonal cycle is similar to Notholt et al. [2010]. The lines in Figure 11 are Rayleigh curves initialized with a number of initial fractionations from a ice-saturated parcel at the height where the mean water vapor is 5 ppmv. The departure from the Rayleigh curve in the present data is suggestive of a role for the sublimation of ice near the tropopause late in the boreal winter, when the Brewer-Dobson circulation is strongest, 
a) convective region

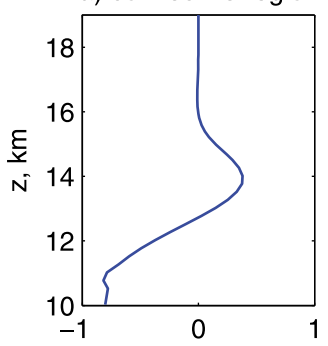

c) subsiding region

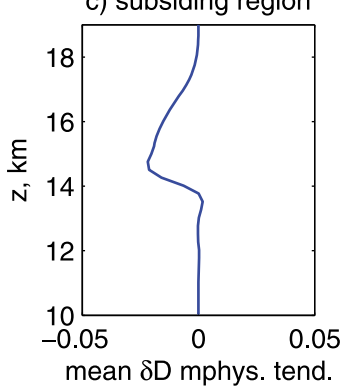

b) convective region: $\delta D$ mphys. tend., per mil $q^{-1}$

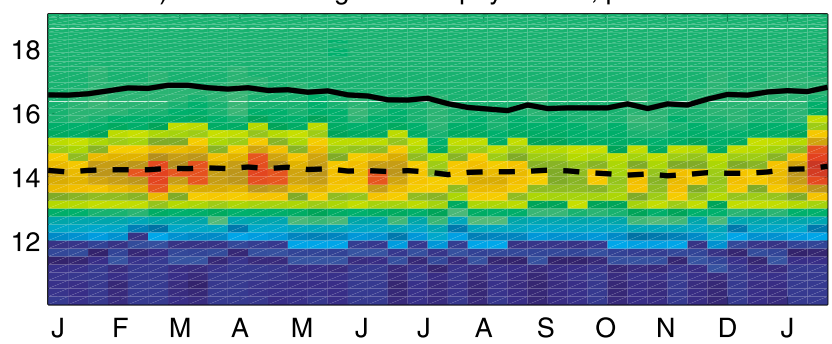

d) subsiding region: $\delta D$ mphys. tend., per mil $d^{-1}$

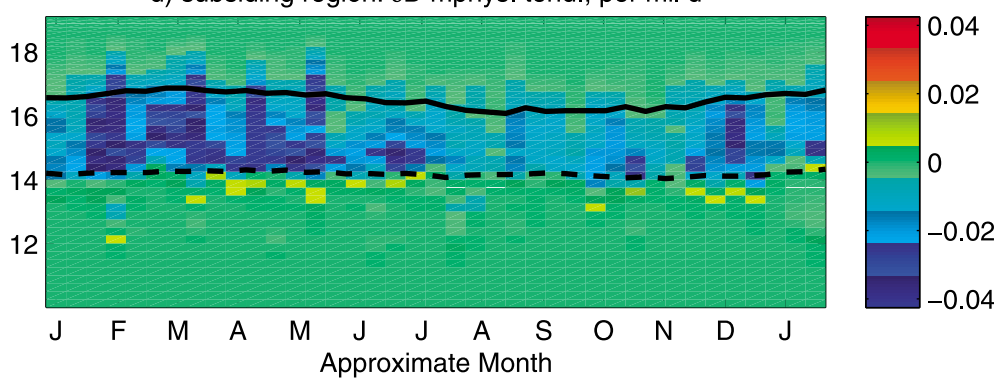

Figure 12. Microphysical tendency of $\delta D$ of water vapor, averaged over $1500 \mathrm{~km}$ columns within the convective and subsiding regions from SEAS. Time-averaged profiles for the (a) convective and (c) subsiding regions. Time and vertical variation of the microphysical source for the (b) convective and (d) subsiding regions. The data in Figures $12 \mathrm{~b}$ and $12 \mathrm{~d}$ have been averaged over each 10 day period for clarity. The heights of the tropopause and the level of zero full sky radiative heating are shown in Figures $12 \mathrm{~b}$ and $12 \mathrm{~d}$ as in Figure 4. Note that $\delta D$ is not a conserved quantity, so that the budget for $\delta D$ is not in general closed.

and this is explored more below. This departure has the opposite sense of the observations from Notholt et al. [2010]. However some care should be taken in the interpretation of the present results. The seasonal forcing of this simulation is limited to the Brewer-Dobson circulation, and this one year simulation will feel some influence from the initial conditions for at least the first few months. Last, the relative dryness of the near-tropopause air in these simulations may increase the potential for isotopic enrichment through the sublimation of lofted ice.
[43] As shown in Figure 12, the microphysical tendency of $\delta D$ of water vapor (see equation (3)) in the TTL atop the convective region acts to damp the seasonal cycle of $\delta D$, while the microphysical tendency of $\delta D$ in the TTL atop the subsiding region is in phase with the seasonal cycle of $\delta D$. This suggests that the sublimation of ice may be responsible for the departure of the seasonal cycle from the Rayleigh curves in Figure 11, which is in the opposite sense to that in the observational data. Both the time-averaged and timevarying profiles of the microphysical tendency of $\delta D$ in the convective and subsiding regions are displayed in Figure 12.
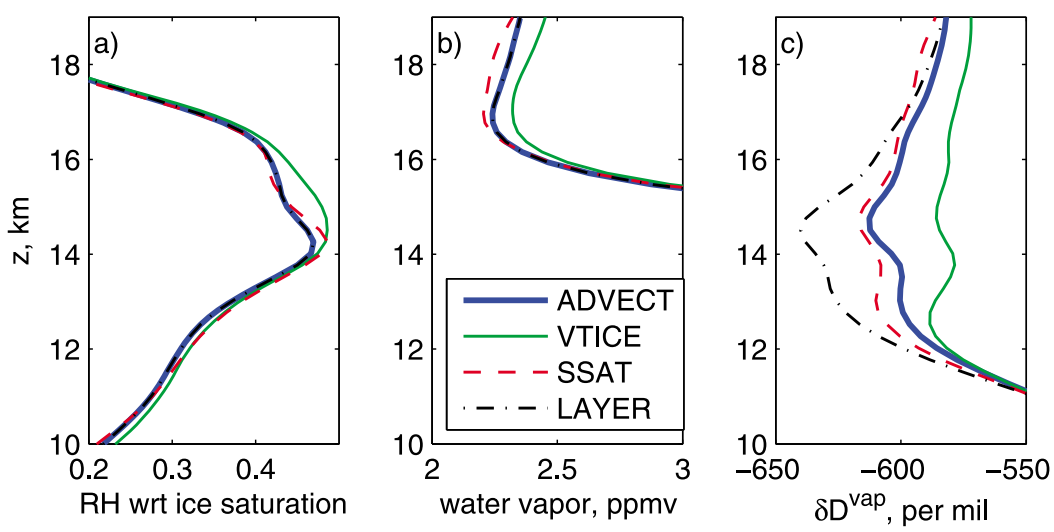

Figure 13. Time-averaged and horizontally averaged profiles of (a) relative humidity with respect to ice saturation, (b) water vapor, and (c) $\delta D$ over days 70-100 of ADVECT, SSAT, VTICE, and LAYER. 

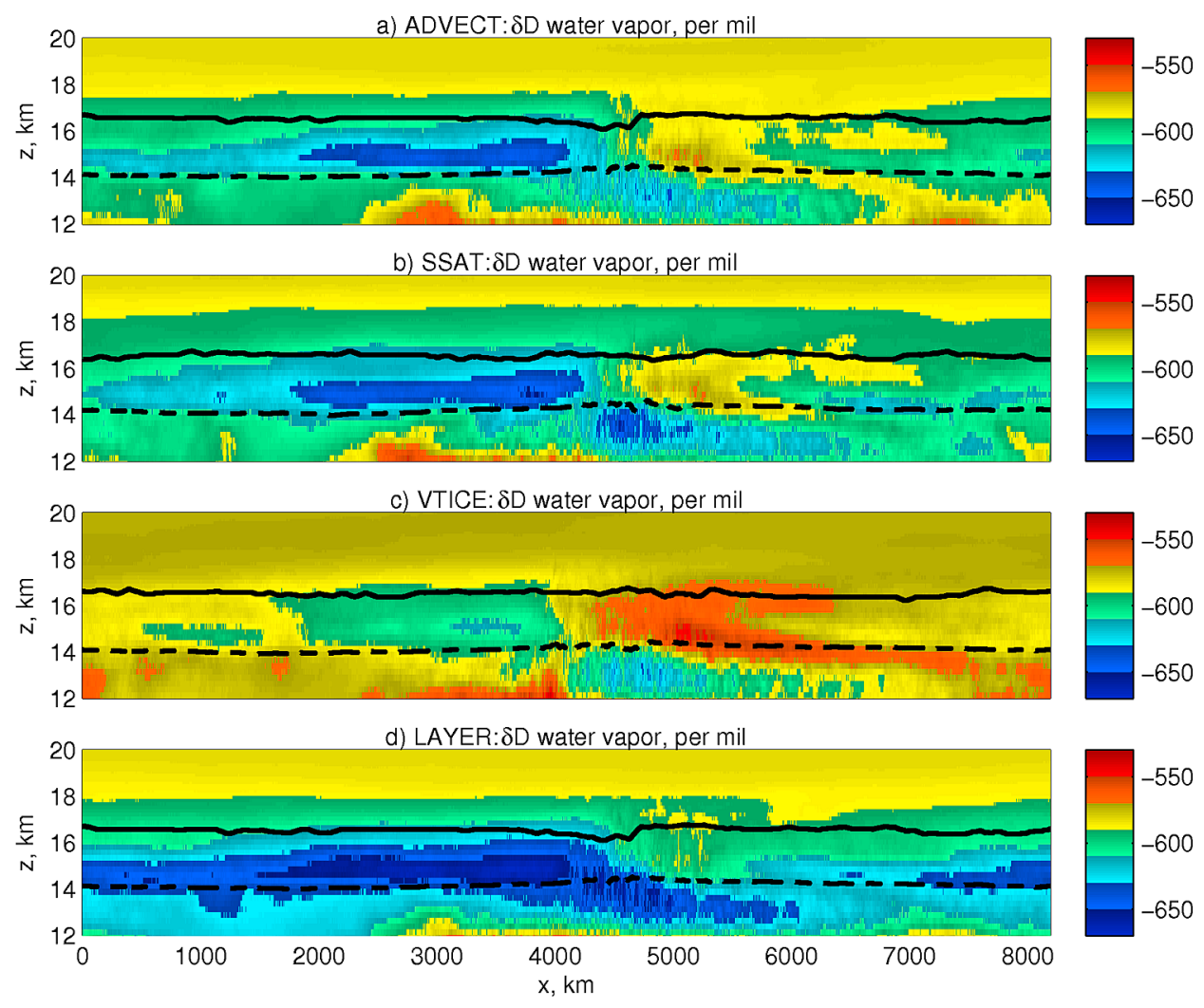

Figure 14. Time-averaged $\delta D$ of vapor in the TTL for (a) ADVECT, (b) SSAT, (c) VTICE, and (d) LAYER. Time averages are taken over days 70-100 for all runs. The tropopause and level of zero radiative heating are plotted as in Figure 4.

Here, these quantities are averaged in the horizontal over $1500 \mathrm{~km}$ areas within each region. Note that while the microphysical tendency of the $\delta D$ of water vapor is larger in the convective region, the subsiding region is more extensive, and the microphysical tendency of $\delta D$ extends higher in the TTL than that of the convective region.

\section{Sensitivities to Microphysical Parameterization}

[44] In this section, additional simulations explore the sensitivity of the results to three aspects of the parameterization of ice: the threshold for nucleation of cloud ice in clear air, the fall speed of cloud ice in thin ice clouds near the tropopause, and the effect of isotopic layering within ice particles on the isotopic content of vapor sublimating from ice.

[45] Significant uncertainty exists regarding the nucleation of cloud ice and the size distribution of ice in thin cirrus clouds near the tropopause [e.g., Jensen et al., 2010]. The microphysical parameterization employed in the present work uses a single-moment, bulk representation of cloud ice. At temperatures colder than those at which cloud water freezes homogeneously $\left(-40^{\circ} \mathrm{C}\right)$, ice cloud is treated in this parameterization as nucleating in clear air when the relative humidity with respect to ice exceeds one. As this approximation is unrealistic, the microphysics were modified in a sensitivity test termed SSAT so that ice cloud will nucleate in cloud-free air at temperature $T<-40^{\circ} \mathrm{C}$ only when the relative humidity with respect to ice exceeds 1.5 . Following nucleation, all supersaturation with respect to ice is removed.

[46] A 100 day simulation has been performed that is identical to ADVECT except for the introduction of ice supersaturation as described above. In the simulation SSAT, the relative humidity with respect to ice saturation (not shown) exceeds one sporadically above the level of homogeneous freezing in the convective region. Note that the supersaturation with respect to ice in the mixed-phase region (between about 5 and $10 \mathrm{~km}$ ) occurs in all simulations presented here and this sensitivity study only affects the nucleation of cloud ice at colder temperatures. The domain-average water vapor, relative humidity and $\delta D$ change little with the addition of ice supersaturation, as seen in Figure 13. Figure 14 shows that the distribution of $\delta D$ is relatively unchanged.

[47] Decreasing the fall speed of thin ice clouds can lead to increases in the water vapor and $\delta D$ of the lower stratosphere, as seen in run VTICE in Figures 13 and 14. The default mass-weighted fallspeed for cloud ice $v_{t}^{i c e}$ in the WRF Lin scheme is that proposed by Heymsfield and Donner [1990],

$$
v_{t}^{i c e}=3.29\left(\rho r_{i}\right)^{0.16},
$$

where $v_{t}^{\text {ice }}$ is in $\mathrm{m} \mathrm{s}^{-1}$, the density of dry air $\rho$ in $\mathrm{kg} \mathrm{m}^{-3}$ and the mass mixing ratio of cloud ice $r_{i}$ in $\mathrm{kg} \mathrm{kg}^{-1}$. This fallspeed relationship was derived from deep ice clouds and 
may not represent well thin ice clouds near the tropopause that may play a role in the regulation of $\delta D$ there. Schmitt and Heymsfield [2009] analyzed a collection of recent in situ observations of low-latitude tropopause cirrus and derived the mass-weighted fallspeed relationship:

$$
v_{t}^{i c e}=2.59\left(\rho r_{i}\right)^{0.2}
$$

which is given in their paper as $v_{m}=65 I W C^{0.2}$ where $v_{m}$ is in $\mathrm{cm} \mathrm{s}^{-1}$ and $I W C$ is in $\mathrm{g} \mathrm{m}^{-3}$. A typical thin cirrus cloud near the tropopause from Schmitt and Heymsfield [2009] has ice water content of $5 \cdot 10^{-7} \mathrm{~kg} \mathrm{~m}^{-3}$ and would have a fallspeed of $0.14 \mathrm{~m} \mathrm{~s}^{-1}$ using equation (5) and $0.32 \mathrm{~m} \mathrm{~s}^{-1}$ using equation (4), the default in the WRF Lin scheme. In simulation VTICE, the Schmitt and Heymsfield [2009] fallspeed relation - equation (5) - was applied fully only at temperatures lower than $-55^{\circ} \mathrm{C}$ and ice water contents less than $5 \mathrm{mg} \mathrm{m}^{-3}$ consistent with ice cloud observations in their paper. Between temperatures of $-55^{\circ} \mathrm{C}$ and $-45^{\circ} \mathrm{C}$ and ice water contents of 5 and $20 \mathrm{mg} \mathrm{m}^{-3}$, a linear combination of the two fall speed relationships is used. At warmer temperatures and in thicker ice clouds, the default fall speed relation from Heymsfield and Donner [1990], equation (4) was used.

[48] The smaller fall speeds of cloud ice will affect the humidity and $\delta D$ of the stratosphere because more of the cloud ice associated with thin clouds that form due to cooling by gravity waves will be retained by the parcel or sublimate closer to the cloud as it falls out. In VTICE, this process leads to a larger water vapor content in the lower stratosphere (Figure 13). In addition, the sublimation of this relatively rich cloud ice increases the $\delta D$ of water vapor entering the lower stratosphere, which is also seen in Figure 14. Note that the vapor is enriched in VTICE relative to ADVECT in both inside and outside of the convective regions. Regions with enriched $\delta D$ in VTICE relative to ADVECT also have larger amounts of water vapor (not shown). While the changes in $\delta D$ between ADVECT and SSAT are smaller, they also appear to be correlated with changes in water vapor amount.

[49] A final sensitivity study (called LAYER) explored the effect of relaxing the assumption that the vapor sublimating from ice would have the mean isotopic content of the ice particle. In reality, the molecular diffusivity in ice is so small that the isotopic content of layers are fixed as they deposit onto the ice. As described in Appendix B5, the vapor produced by sublimation in this sensitivity study has a composition characteristic of that which would be deposited onto ice at the current temperature. This is motivated by the notion that the outer layers of an ice particle have been deposited recently in conditions similar to those currently prevailing around the particle and that the isotopic content of the vapor produced by sublimation is in reality determined by these outer layers and not by the mean isotopic composition of the particle.

[50] This sensitivity study produces the strongest changes in the isotopic composition of the TTL among those considered here. As this sensitivity study does not alter the standard water microphysics, there are no changes in the water vapor and relative humidity profiles as seen in Figures $13 \mathrm{a}$ and $13 \mathrm{~b}$. The isotopic content of water vapor is depleted with respect to the control simulation (ADVECT) around the base of the TTL (from 12-15 km, Figures 13c and $14 \mathrm{~d}$ ). This level corresponds to the location of the microphysical source of $\delta D$ seen in NOADV and ADVECT in Figures 4e and 4k. In LAYER, this source remains, but is weaker than in those simulations (not shown). While the assumption that vapor sublimating from ice apparently overestimates the strength of this source of $\delta D$, the existence of this source is robust to this simplified implementation of the effects of layering on sublimation.

\section{Summary and Discussion}

[51] Through detailed, long-term, idealized simulations that mimic some aspects of the equatorial Walker circulation, the processes that fix the isotopic composition of water vapor in the tropical tropopause layer (TTL) have been explored. Idealized simulations without mean advection through the TTL exhibited two different mechanisms that acted to fix the isotopic content of water entering the stratosphere: convection and in situ cirrus cloud formation. The variability in the isotopic content of water vapor entering the stratosphere was larger than observed. The addition of a mean flow through the TTL (and shear through the troposphere) reduced the variability in water vapor and isotopic composition in the TTL and produced isotopic compositions of water vapor similar to those observed. In both settings, microphysical processes are found to deplete the $\delta D$ of water vapor in the lower and mid troposphere and to enrich it in the TTL above the region of deep convection. Mixing also likely plays a role in fixing the fractionation of water vapor in the TTL by reducing the variability in $\delta D$ as air ascends through the TTL, as suggested previously by Dessler and Sherwood [2003] and Kuang et al. [2003].

[52] When a simulation is forced by a seasonally varying Brewer-Dobson circulation, a seasonal cycle in water vapor and $\delta D$ in the TTL is found whose structure emulates the tape recorder of Mote et al. [1995]. The amplitude of the seasonal cycle decreases with altitude, though somewhat faster than seen by Steinwagner et al. [2010]. The amplitude of the seasonal cycle of $\delta D$ in the vicinity of the tropopause is smaller than that observed by Notholt et al. [2010] but similar to that of Steinwagner et al. [2010], whose measurements have coarser vertical resolution. The phase of the seasonal cycle in $\delta D$ is also comparable to that observed by Steinwagner et al. [2010].

[53] The results suggest that both cirrus cloud formation and the lofting of ice by deep convection are important for fixing the isotopic fractionation of water vapor in the TTL. The sensitivity of $\delta D$ to seasonal variations in the BrewerDobson circulation points to a role for both cirrus cloud formation and convective ice lofting in fixing the final isotopic composition of vapor crossing the tropopause. In the present simulation, variations in convective processes seem to damp the seasonal cycle of $\delta D$ of water vapor.

[54] The treatment of ice is highly simplified in this model, and the sensitivity of the results to three aspects of this treatment - supersaturation with respect to ice in cloudfree air, the fall speed of cloud ice in thin, cold clouds, and the effect of layering on the isotopic composition of vapor sublimating from ice-has been characterized. While introducing supersaturation with respect to ice caused no significant change of $\delta D$, using an observationally derived 
fall speed relationship for cloud ice in thin, cold clouds resulted in an increase in both the humidity and $\delta D$ of air entering the stratosphere. An approximate treatment of layering suggests that neglecting the effect of isotopic layering within an ice particle on sublimation will lead to an overestimation of the enrichment of water vapor in the TTL by sublimating ice lofted by convection. However, even with this approximate treatment of layering, the microphysical tendency of $\delta D$ at the base of the TTL atop the convective region remained positive, suggesting that the role of convection in enriching the TTL is robust with respect to the treatment of isotopic layering in these simulations.

[55] These simulations are limited in their ability to represent the processes that fix the isotopic composition of the air entering the stratosphere by their simplified treatment of microphysical processes as well as their dimensionality, resolution and idealized framework. However, the duration of the simulations in this paper allows the evolution and equilibration of the TTL over the long time scales associated with radiation and transport by the Brewer-Dobson circulation. Further, the explicit representation of convective processes and mixing in these simulations does represent more of the variability of water vapor amount and isotopic composition that exists in the TTL than is possible in GCMs and also in simpler frameworks, such as trajectory, parcel or single column models.

\section{Appendix A: Brewer-Dobson Circulation}

[56] The Brewer-Dobson circulation used in the present simulations is modeled after the observationally derived mass fluxes of Yang et al. [2008]. The functional form of the vertical mass flux includes a vertically uniform part and a part that decays with height above $100 \mathrm{hPa}$ :

$$
\begin{aligned}
M(p, t)= & f(p)\left[a_{1}\left(1+b_{1} \cos \left(2 \pi \frac{t-t_{1}}{T}\right)\right)\right. \\
& \left.+a_{2}\left(1+b_{2} \cos \left(2 \pi \frac{t-t_{2}}{T}\right)\right) \exp \left(-\left(\frac{p^{\prime}-p_{0}}{p_{h}}\right)^{2}\right)\right]
\end{aligned}
$$

where $p^{\prime}=\min \left(p, p_{0}\right)$ and $f(p)=\max \left(0, \min \left(1,\left(p-p_{2}\right) /\right.\right.$ $\left.\left.\left(p_{1}-p_{2}\right)\right)\right)$ with $p_{0}=100 \mathrm{hPa}, p_{1}=30 \mathrm{hPa}$ and $p_{2}=1 \mathrm{hPa}$. Here, the period of the seasonal cycle is $T=365$ days, the mass flux is maximized at $p_{0}(100 \mathrm{hPa})$ and falls off above $p_{0}$ like Gaussian with half-width $p_{h}=20 \mathrm{hPa}$. Below $p_{0}$, the mass flux is uniform in the vertical. All simulations in this paper use $a_{1}=1 \mathrm{~kg} \mathrm{~m}^{-2} \mathrm{~d}^{-1}$ and $a_{2}=5 \mathrm{~kg} \mathrm{~m}^{-2} \mathrm{~d}^{-1}$. The runs without a seasonal cycle (NOADV, ADVECT, VTICE, SSAT, LAYER) use with $b_{1}=b_{2}=0$, while the run with a seasonally varying Brewer-Dobson circulation (SEAS) uses $b_{1}=0.5, t_{1}=23$ days, $b_{2}=0.5$ and $t_{2}=68$ days. Note that the phase of the two components of the Brewer-Dobson circulation differ, with the vertically uniform part having maximum amplitude in January (assuming $t=0$ corresponds to 0000 UT on 1 January) and the vertically varying part strongest in early March.

\section{Appendix B: Treatment of Isotope Microphysics}

[57] The underlying microphysics parameterization that we are using is the six-class single-moment Lin scheme [ $\operatorname{Lin}$ et al., 1983]. The six classes are vapor, cloud liquid, cloud ice, rain, snow, and graupel; these categories of water will be denoted by subscripts $v, c, i, r, s$, and $g$, respectively. For example, $\rho_{v}$ will be the density of water vapor and $r_{v}$ will be the mass mixing ratio of water vapor. We will also be using $l$ and $s$ to denote liquid and solid water; the distinction between $s$ for snow and $s$ for solid will be clear from the context.

[58] We have augmented this Lin scheme with twelve new classes corresponding to the heavy versions (HDO and $\mathrm{H}_{2}^{18} \mathrm{O}$ ) of the original light classes $\left(\mathrm{H}_{2} \mathrm{O}\right)$. Most microphysical processes are treated identically for $\mathrm{H}_{2} \mathrm{O}$, HDO, and $\mathrm{H}_{2}^{18} \mathrm{O}$. For example, if $P_{\text {SAUT }}$ is the mass source of light snow from the autoconversion of light ice, the source of HDO snow from the autoconversion of HDO ice is $\frac{r_{i}^{\prime}}{r_{i}} P_{\text {SAUT }}$, where $r_{i}$ is the mass mixing ratio of light ice and $r_{i}^{\prime}$ is the mass mixing ratio of HDO ice. Since light and heavy isotopes are transferred from ice to snow in proportion to their ratios in ice, there is no fractionation.

[59] Fractionation is assumed to take place only during microphysical processes mediated by diffusion through the vapor phase. For example, these include condensation of vapor onto cloud liquid and rain, evaporation of cloud liquid and rain into vapor, and deposition of vapor onto ice and snow. The remainder of this appendix is devoted to deriving the effect of these processes on the mixing ratios of the heavy water classes.

\section{B1. Diffusive Exchange With Surrounding Vapor}

[60] For completeness, we begin by deriving the expression for the steady state flux of water vapor onto a spherically symmetric particle, which is treated in many texts [e.g., Houze, 1993]. Let $D_{v}$ be the molecular diffusivity of light (i.e., $\mathrm{H}_{2} \mathrm{O}$ ) water vapor in air. Let us also consider a spherically symmetric distribution of water vapor, as might be expected around a suspended liquid droplet. In spherical coordinates, the diffusive flux of water vapor is $-D_{v} \partial_{r} \rho_{v} \hat{r}$, where $\hat{r}$ is the unit vector in the radial direction. The convergence of water vapor, $D_{v} \nabla^{2} \rho_{v}$, is then

$$
\frac{D_{v}}{r} \partial_{r}^{2}\left(r \rho_{v}\right)
$$

where $D_{v}$ has been assumed to be spatially uniform. In a steady state with fixed boundary conditions, this convergence of diffusive mass flux must be zero. This implies that $\rho_{v}$ takes the form

$$
\rho_{v}(r)=A+\frac{B}{r}
$$

Given $\rho_{v}(r)$ at the surface of the drop $(r=a)$ and far from the drop $(r=\infty)$ we can solve for $A$ and $B$ to find

$$
\rho_{v}(r)=\rho_{v}(a)+\left[\rho_{v}(a)-\rho_{v}(\infty)\right]\left(\frac{a}{r}-1\right) .
$$

The rate of mass accretion onto the drop is equal to $-4 \pi r^{2}$ times the radial component of the diffusive flux, which gives

$$
\frac{d m}{d t}=4 \pi r^{2} f D_{v} \partial_{r} \rho_{v}(r)=-4 \pi a f D_{v}\left[\rho_{v}(a)-\rho_{v}(\infty)\right] .
$$

Here, we have added the ventilation factor, $f$, which accounts for the enhancement of diffusive flux when the 
drop is moving relative to the ambient air. Similarly, the rate at which heat is added to the drop is given by

$$
Q=-4 \pi a f k[T(a)-T(\infty)]
$$

where $k$ is the thermal conductivity.

[61] In a steady state, the flux of heat away from the drop must be equal to the release of latent heat, which is equal to the rate at which mass is condensed onto the drop, $d m / d t$, times the latent heat of condensation, $L_{c}$. Therefore,

$$
\frac{d m}{d t} L_{c}+Q=0
$$

or

$$
k[T(a)-T(\infty)]=-D_{v}\left[\rho_{v}(a)-\rho_{v}(\infty)\right] L_{c} .
$$

Note that $\rho_{v}(a)$ equals the saturation vapor density over liquid at the temperature $T(a), \rho_{v}^{*, l}[T(a)]$. Here, we use a superscript asterisk to denote the saturation value and the superscript $l$ to denote that this is the saturation value with respect to liquid. Since

$$
\frac{d \rho_{v}^{*, l}}{d T} \approx \frac{\rho_{v}^{*, l} L_{c}}{R_{v} T^{2}}
$$

we can Taylor expand $\rho_{v}(a)=\rho_{v}^{*, l}[T(a)]$ in $\Delta T \equiv T(a)-T(\infty)$ to rewrite equations (B1) and (B3) as

$$
\begin{aligned}
& \frac{d m}{d t}=-4 \pi a f D_{v}\left[1+\frac{L_{c} \Delta T}{R_{v} T^{2}}-S_{l}\right] \rho_{v}^{*, l}[T(\infty)] \\
& k \Delta T=-D_{v}\left[1+\frac{L_{c} \Delta T}{R_{v} T^{2}}-S_{l}\right] \rho_{v}^{*, l}[T(\infty)] L_{c},
\end{aligned}
$$

where $S_{l}$ is the ratio of $\rho_{v}(\infty)$ to $\rho_{v}^{*, l}[T(\infty)]$, which is roughly equal to the relative humidity. Equation (B5) may be rearranged to give

$$
\Delta T=-\frac{D_{v}\left(1-S_{l}\right) \rho_{v}^{*, l} L_{c}}{k+D_{v} \frac{L_{c}^{2}}{R_{v} T^{2}} \rho_{v}^{*, l}}
$$

where we have dropped the reminder that $\rho_{v}^{*, l}$ is evaluated at the ambient temperature, $T(\infty)$. Substituting equation (B6) into equation (B4), we get

$$
\frac{d m}{d t}=-4 \pi a f D_{v} \frac{1-S_{l}}{1+b_{l}} \rho_{v}^{*, l}
$$

where

$$
b_{l} \equiv \frac{D_{v} L_{c}^{2} \rho_{v}^{*, l}}{k R_{v} T^{2}}
$$

[62] If we want to be more accurate, we can follow Srivastava and Coen [1992] and Taylor expand to second order in the temperature difference using

$$
\frac{d^{2} \rho_{v}^{*, l}}{d T^{2}} \approx \frac{\rho_{v}^{*, l} L_{c}^{2}}{R_{v}^{2} T^{4}}
$$

By Taylor expanding $\rho_{v}(a)=\rho_{v}^{*, l}[T(a)]$ in $\Delta T \equiv T(a)-T(\infty)$ to second order, we can rewrite equations (B1) and (B3) as

$$
\begin{aligned}
& \frac{d m}{d t}=-4 \pi a f D_{v}\left[1+\frac{L_{c} \Delta T}{R_{v} T^{2}}+\frac{L_{c}^{2} \Delta T^{2}}{2 R_{v}^{2} T^{4}}-S_{l}\right] \rho_{v}^{*, l}[T(\infty)] \\
& k \Delta T=-D_{v}\left[1+\frac{L_{c} \Delta T}{R_{v} T^{2}}+\frac{L_{c}^{2} \Delta T^{2}}{2 R_{v}^{2} T^{4}}-S_{l}\right] \rho_{v}^{*, l}[T(\infty)] L_{c} .
\end{aligned}
$$

Equation (B9) may be rearranged to give

$$
\frac{L_{c}^{2}}{2 R_{v}^{2} T^{4}} \Delta T^{2}+\left(\frac{k}{D_{v} \rho_{v}^{*, l} L_{c}}+\frac{L_{c}}{R_{v} T^{2}}\right) \Delta T+\left(1-S_{l}\right)=0 .
$$

where we have dropped the reminder that $\rho_{v}^{*, l}$ is evaluated at the ambient temperature, $T(\infty)$. This quadratic equation can be solved for $\Delta T$, yielding

$$
\begin{aligned}
\Delta T= & \frac{R_{v}^{2} T^{4}}{L_{c}^{2}}\left(\frac{k}{D_{v} \rho_{v}^{*, l} L_{c}}+\frac{L_{c}}{R_{v} T^{2}}\right) \\
& \cdot\left[-1 \pm \sqrt{1-\frac{2 L_{c}^{2}}{R_{v}^{2} T^{4}}\left(\frac{k}{D_{v} \rho_{v}^{*, l} L_{c}}+\frac{L_{c}}{R_{v} T^{2}}\right)^{-2}\left(1-S_{l}\right)}\right] .
\end{aligned}
$$

Since $\Delta T$ must go to zero when $S_{l}=1$, we pick the solution with the plus sign. Expanding the square root to second order in $1-S_{l}$, we get

$$
\begin{aligned}
\Delta T= & -\frac{D_{v} \rho_{v}^{*, l} L_{c}}{k+D_{v} \frac{L_{c}^{2}}{R_{v} T^{2}} \rho_{v}^{*, l}}\left(1-S_{l}\right) \\
& -\frac{L_{c}^{2}}{2 R_{v}^{2} T^{4}}\left(\frac{D_{v} \rho_{v}^{*, l} L_{c}}{k+D_{v} \frac{L_{c}^{2}}{R_{v} T^{2}} \rho_{v}^{*, l}}\right)^{3}\left(1-S_{l}\right)^{2} .
\end{aligned}
$$

Substituting equation (B10) into equation (B8) and keeping terms up to second order in $1-S_{l}$, we obtain

$$
\frac{d m}{d t}=-4 \pi a f D_{v}\left[1+\frac{1}{2}\left(\frac{b_{l}}{1+b_{l}}\right)^{2}\left(1-S_{l}\right)\right] \frac{1-S_{l}}{1+b_{l}} \rho_{v}^{*, l} .
$$

We will write equations (B7) and (B11) as

$$
\frac{d m}{d t}=4 \pi a f D_{v}\left(1-\beta_{l}\right) \frac{S_{l}-1}{1+b_{l}} \rho_{v}^{*, l},
$$

where

$$
\beta_{l}= \begin{cases}0 & \text { to first order in } \Delta T \text { and } 1-S_{l} \\ \frac{1}{2}\left(\frac{b_{l}}{1+b_{l}}\right)^{2}\left(S_{l}-1\right) & \text { to second order in } \Delta T \text { and } 1-S_{l} .\end{cases}
$$

The underlying microphysical package that we are modifying does not account for the second-order effects in $\Delta T$ or $S_{l}-1$, so we use $\beta_{l}=0$. Since future work will likely use 
schemes that account for second-order effects [e.g., Thompson et al., 2008], we include $\beta_{l}$ here for reference.

[63] The preceding derivation applies to any kind of liquid drop, be it a small drop of cloud liquid or a larger raindrop. For specificity, let us now consider the case of a raindrop. We will denote the mixing ratios of light vapor and rain as $r_{v}$ and $r_{r}$. In what follows, we will denote quantities associated with heavy isotopes by a prime. For example, we will denote the heavy mixing ratios of vapor and rain (for, say, HDO) as $r_{v}^{\prime}$ and $r_{r}^{\prime}$.

\section{B2. Diffusive Exchange of Heavy Water With Surrounding Vapor}

[64] Fractionation occurs because of two important differences between light and heavy water. First, heavy water vapor has an effective diffusivity, $f^{\prime} D_{v}^{\prime}$, that differs from $f D_{v}$. Second, at a raindrop-air interface in equilibrium, the ratio of masses in the drop, $\mathrm{m}^{\prime} / \mathrm{m}$, does not equal $\rho_{v}^{\prime} / \rho_{v}$ just outside the drop; the equilibrium fractionation factor over liquid, $\alpha_{l} \equiv$ $\left(m^{\prime} / m\right) \div\left(\rho_{v}^{\prime} / \rho_{v}\right)$, is greater than one, reflecting the predilection of heavy water to reside in the condensed phase.

[65] Therefore, to derive the heavy-isotope version of equation (B7), we can repeat the preceding derivation by using $f^{\prime} D_{v}^{\prime}$ in place of $f D_{v}$ and by recognizing that the density of heavy vapor at $r=\infty$ is $\frac{r_{v}^{\prime}}{r_{v}} S_{l} \rho_{v}^{*, l}$ and, to first order in $\Delta T$, the density at $r=a$ is

$$
\frac{m^{\prime}}{m} \frac{1}{\alpha_{l}}\left(1+\frac{L_{c} \Delta T}{R_{v} T^{2}}\right) \rho_{v}^{*, l}
$$

Here, we assume that the isotopic composition at the surface is equal to the mean isotopic composition of the droplet or particle. We further assume that the isotope ratio is independent of drop size. For example, if this is a raindrop, then we can replace $m^{\prime} / m$ with $r_{r}^{\prime} / r_{r}$. Then, the rate at which heavy vapor is accreted onto the drop-the analogue of equation (B4) - is found to be

$$
\frac{d m^{\prime}}{d t}=-4 \pi a f^{\prime} D_{v}^{\prime}\left[\frac{r_{r}^{\prime}}{r_{r}} \frac{1}{\alpha_{l}}\left(1+\frac{L_{c} \Delta T}{R_{v} T^{2}}\right)-\frac{r_{v}^{\prime}}{r_{v}} S_{l}\right] \rho_{v}^{*, l} .
$$

Substituting the expression for $\Delta T$ from equation (B6), we get the heavy-isotope version of equation (B7),

$$
\frac{d m^{\prime}}{d t}=-4 \pi a f^{\prime} D_{v}^{\prime}\left[\frac{r_{r}^{\prime}}{r_{r}} \frac{1}{\alpha_{l}} \frac{1+b_{l} S_{l}}{1+b_{l}}-\frac{r_{v}^{\prime}}{r_{v}} S_{l}\right] \rho_{v}^{*, l}
$$

Equations (B7) and (B14) are equivalent to equations (16) and (17) of Gedzelman and Arnold [1994], except for the inclusion of the ventilation factor in the present equations and two typographical errors in Gedzelman and Arnold [1994]. Note that $r_{v}^{\prime} / r_{v}$ and $r_{r}^{\prime} / r_{r}$ are ratios of mass mixing ratios, so that the mass ratio does not appear separately as a factor in (B14) as it does in equation (17) of Gedzelman and Arnold [1994].

[66] To second order, the heavy-vapor density at $r=a$ is

$$
\frac{r_{r}^{\prime}}{r_{r}} \frac{1}{\alpha_{l}}\left(1+\frac{L_{c} \Delta T}{R_{v} T^{2}}+\frac{L_{c}^{2} \Delta T^{2}}{2 R_{v}^{2} T^{4}}\right) \rho_{v}^{*, l}
$$

Therefore, the rate at which the mass of heavy isotope is accreted onto the drop - the analogue of equation (B8) - is

$$
\frac{d m^{\prime}}{d t}=-4 \pi a f^{\prime} D_{v}^{\prime}\left[\frac{r_{r}^{\prime}}{r_{r}} \frac{1}{\alpha_{l}}\left(1+\frac{L_{c} \Delta T}{R_{v} T^{2}}+\frac{L_{c}^{2} \Delta T^{2}}{2 R_{v}^{2} T^{4}}\right)-\frac{r_{v}^{\prime}}{r_{v}} S_{l}\right] \rho_{v}^{*, l} .
$$

Substituting the expression for $\Delta T$ from equation (B10) and keeping second-order terms in $1-S_{l}$, we get the heavyisotope version of equation (B11),

$$
\frac{d m^{\prime}}{d t}=-4 \pi a f^{\prime} D_{v}^{\prime}\left[\frac{r_{r}^{\prime}}{r_{r}} \frac{1}{\alpha_{l}}\left(\frac{1+b_{l} S_{l}}{1+b_{l}}+\frac{b_{l}^{2}\left(1-S_{l}\right)^{2}}{2\left(1+b_{l}\right)^{3}}\right)-\frac{r_{v}^{\prime}}{r_{v}} S_{l}\right] \rho_{v}^{*, l} .
$$

Using $\beta_{l}$, we can write both (B14) and (B16) as

$$
\frac{d m^{\prime}}{d t}=-4 \pi a f^{\prime} D_{v}^{\prime}\left[\frac{r_{r}^{\prime}}{r_{r}} \frac{1}{\alpha_{l}}\left(1+\left(b_{l}+\beta_{l}\right) \frac{S_{l}-1}{1+b_{l}}\right)-\frac{r_{v}^{\prime}}{r_{v}} S_{l}\right] \rho_{v}^{*, l}
$$

[67] Let us denote the number of raindrops per cubic meter within the diameter range of $[a, a+d a]$ by $n_{r}(a) d a$. The change in raindrop mixing ratios, $r_{r}$ and $r_{r}^{\prime}$, are then related to $n_{r}(a), m(a)$, and $m^{\prime}(a)$ by

$$
\begin{aligned}
\frac{d r_{r}}{d t} & =\frac{1}{\rho_{a}} \int_{0}^{\infty} d a n_{r}(a) \frac{d m(a)}{d t} \\
\frac{d r_{r}^{\prime}}{d t} & =\frac{1}{\rho_{a}} \int_{0}^{\infty} d a n_{r}(a) \frac{d m^{\prime}(a)}{d t},
\end{aligned}
$$

where $\rho_{a}$ is the density of dry air. Using equations (B12) and (B17), these become

$$
\begin{gathered}
\frac{d r_{r}}{d t}=C_{r} f D_{v}\left(1-\beta_{l}\right) \frac{S_{l}-1}{1+b_{l}} \\
\frac{d r_{r}^{\prime}}{d t}=C_{r} f^{\prime} D_{v}^{\prime}\left[\frac{r_{v}^{\prime}}{r_{v}} S_{l}-\frac{r_{r}^{\prime}}{r_{r}} \frac{1}{\alpha_{l}}\left(1+\left(b_{l}+\beta_{l}\right) \frac{S_{l}-1}{1+b_{l}}\right)\right],
\end{gathered}
$$

where

$$
C_{r} \equiv 4 \pi \frac{\rho_{v}^{*, l}}{\rho_{a}} \int_{0}^{\infty} d a n_{r}(a) a .
$$

Care should be taken that the factor of $C_{r}$ used in the numerical implementation of equation (B19) matches that from the numerical implementation of (B18) so that no spurious fractionation is generated through inconsistencies between these two equations. Note that $C_{r}$ cannot be eliminated by expressing $d r_{r}^{\prime} / d t$ as a multiple of $d r_{r} / d t$ because isotopic exchange (equilibration) can occur when $S_{l}=1$.

\section{B3. Exchange Between Cloud Liquid and Vapor}

[68] The derivation for nonprecipitating cloud goes through the same as for rain; the only difference is the size of the drops. For a fixed mass of cloud liquid, the number concentration $n_{c}$ scales as $1 / a^{3}$, where $a$ is the characteristic diameter of the droplets. Therefore, $C_{c}$ scales as $1 / a$, where 
$C_{c}$ is computed for cloud as in (B20). For the small droplets that comprise the cloud class in microphysics schemes, $C_{c}$ is so large that the $S_{l}-1$ in equation (B18) may be approximated as zero. Therefore, microphysical schemes, such as the Lin scheme, use a saturation adjustment at every time step to enforce $S_{l}=1$ within liquid clouds. By the same reasoning, we may approximate the term in square brackets on the right-hand side of equation (B19) as zero for cloud. This produces a diagnostic relation for $r_{c}^{\prime}$,

$$
r_{c}^{\prime}=\frac{r_{v}^{\prime}+r_{c}^{\prime}}{1+\frac{r_{v}}{r_{c}} \frac{1}{\alpha_{l}}}
$$

The approach here follows that of Ciais and Jouzel [1994], who also argued that the time scale for the adjustment to isotopic equilibrium of liquid droplets less than $30 \mu \mathrm{m}$ (roughly the maximum diameter of cloud liquid droplets) was on the order of a couple of seconds - comparable to the time steps in the simulations here.

[69] Mixed-phase clouds are, by definition, out of equilibrium, so approximating $C_{c}$ as infinite is unphysical. Instead, to allow for an $r_{v}$ in between that of $r_{v}^{*, l}$ and $r_{v}^{*, s}$ (the saturation mixing ratios with respect to liquid and solid), $C_{c}$ and $C_{i}$ would need to be treated as finite. In that case, equations (B18) and (B19) that govern the isotopic exchange between liquid droplets and vapor could be combined to give the following equation:

$$
\begin{aligned}
\frac{d r_{c}{ }^{\prime}}{d t}= & \frac{f^{\prime} D_{v}^{\prime}}{f D_{v}} \frac{1+b_{l}}{\left(1-\beta_{l}\right)\left(S_{l}-1\right)} \\
& \cdot\left[\frac{r_{v}^{\prime}}{r_{v}} S_{l}-\frac{r_{c}^{\prime}}{r_{c}} \frac{1}{\alpha_{l}}\left(1+\left(b_{l}+\beta_{l}\right) \frac{S_{l}-1}{1+b_{l}}\right)\right] \frac{d r_{c}}{d t},
\end{aligned}
$$

where $r_{r}$ and $r_{r}^{\prime}$ replaced with $r_{c}$ and $r_{c}{ }^{\prime}$. But, in the microphysics scheme that we are modifying, an instantaneous saturation adjustment is used even for mixed-phase cloud. When the air temperature is between the freezing temperature and $-40^{\circ} \mathrm{C}$, then the saturation mass fraction of vapor is defined as

$$
r_{v}^{*}=(1-\xi) r_{v}^{*, l}+\xi r_{v}^{*, s},
$$

where

$$
\xi \equiv \begin{cases}\frac{r_{i}}{r_{c}+r_{i}} & \text { where } r_{c}+r_{i}>0 \\ \max \left(0, \min \left(1, \frac{273.15-T}{25}\right)\right) & \text { elsewhere. }\end{cases}
$$

and $\mathrm{T}$ is given in Kelvin. When $r_{v}$ deviates from $r_{v}^{*}$, the saturation adjustment scheme redistributes mass among cloud liquid, cloud ice, and vapor according to

$$
\begin{aligned}
d r_{c} & =-(1-\xi) d r_{v} \\
d r_{i} & =-\xi d r_{v},
\end{aligned}
$$

where $d r_{v}$ is chosen such that the new $r_{v}$ will equal the new $r_{v}{ }^{*}$. This means that water vapor can condense onto liquid water even though $r_{v}$ remains between $r_{v}^{*, l}$ and $r_{v}^{*, s}$. Therefore, $d r_{c} l$ $d t$ can be positive even though $S_{l}-1$ is negative. This implies that, in the cloud version of equation (B18), $C_{c}$ is negative, which is unphysical. This manifests itself as a pathology in equation (B22). To see why, note that $\beta_{l}<1$, so the sign of $d r_{c}^{\prime} / d t$ is determined by the signs of $S_{l}-1$, the expression in square brackets, and $d r_{c} / d t$. If $r_{c}^{\prime}=0$, then the term in square brackets is positive, so a positive $d r_{c} / d t$ and a negative $S_{l}-1$ produce a negative $d r_{c}^{\prime} / d t$. Since $r_{c}^{\prime}=0$, this would produce a negative mixing ratio of heavy cloud liquid. Therefore, we ignore kinetic fractionation of cloud liquid in mixed-phase clouds and use, as we do when $T>0{ }^{\circ} \mathrm{C}$, the equilibrium fractionation given by equation (B21). In this way, the present approach diverges from Ciais and Jouzel [1994], who included kinetic effects in exchanges between cloud liquid and vapor in their parameterization of the Bergeron process.

\section{B4. Deposition Onto Ice}

[70] The diffusivity of heavy water within ice is so small that layers of isotopically distinct composition are accumulated onto an ice particle as vapor is deposited. For an illustration of this effect, see the isotopic cross section of hailstones depicted by Jouzel et al. [1975]. As the water vapor interacts with only a thin diffusion layer at the surface of the particle during deposition, we may approximate the ratio of isotope masses in that outer layer as equal to the ratio of isotope fluxes onto the particle. Therefore, the version of equation (B19) appropriate for ice has $r_{r}^{\prime} / r_{r}$ replaced with $\left(d r_{i}^{\prime} / d t\right) /\left(d r_{i} / d t\right)$, and similarly for snow and graupel. In addition, for ice, snow, and graupel, we must replace $\alpha_{l}$ with the fractionation factor over solid water, $\alpha_{s}$, and we must account for the latent heat of fusion, $L_{f}$, by replacing $S_{l}$ with $S_{s} \equiv \rho_{v} / \rho_{v}^{*, s}$, where $\rho_{v}^{*, s}$ is the saturation vapor density over solid water, and by replacing $b_{l}$ with

$$
b_{s} \equiv \frac{D_{v}\left(L_{c}+L_{f}\right)^{2} \rho_{v}^{*, s}}{k R_{v} T^{2}} .
$$

Then, for ice, we get

$$
\frac{d r_{i}}{d t}=C_{i} f D_{v}\left(1-\beta_{s}\right) \frac{S_{s}-1}{1+b_{s}}
$$

$$
\frac{d r_{i}^{\prime}}{d t}=C_{i} f^{\prime} D_{v}^{\prime}\left[\frac{r_{v}^{\prime}}{r_{v}} S_{s}-\frac{d r_{i}^{\prime} / d t}{d r_{i} / d t} \frac{1}{\alpha_{s}}\left(1+\left(b_{s}+\beta_{s}\right) \frac{S_{s}-1}{1+b_{s}}\right)\right]
$$

where

$$
\beta_{s}= \begin{cases}0 & \text { to first order in } \Delta T \text { and } 1-S_{s} \\ \frac{1}{2}\left(\frac{b_{s}}{1+b_{s}}\right)^{2}\left(S_{s}-1\right) & \text { to second order in } \Delta T \text { and } 1-S_{s}\end{cases}
$$

After using (B23) to eliminate $C_{i}$ in (B24), we get

$$
\frac{d r_{i}^{\prime}}{d t}=\alpha_{s} \alpha_{k} \frac{r_{v}^{\prime}}{r_{v}} \frac{d r_{i}}{d t}
$$

where

$$
\alpha_{k}=\frac{\left(1+b_{s}\right) S_{s}}{\alpha_{s} \frac{f D_{v}}{f^{\prime} D_{v}^{\prime}}\left(S_{s}-1\right)\left(1-\beta_{s}\right)+\left[1+b_{s} S_{s}+\beta_{s}\left(S_{s}-1\right)\right]} .
$$


Equations (B25) and (B26) are equivalent to the result obtained by combining equations (11) and (14) of Jouzel and Merlivat [1984] if their $A$ is replaced by $1+b_{s}$. Because the microphysics scheme uses a saturation adjustment in mixed-phase cloud, $d r_{i} / d t$ can be negative even though $S_{s}-1$ is positive. From equation (B23), this implies that $C_{i}$ is negative, which is unphysical. But, this does not produce a pathology in equation (B25). To see why not, note that $\alpha_{s}>1, f D_{v} / f^{\prime} D_{v}^{\prime}>1$, and that $S_{s}<3 \rightarrow \beta_{s}<1$. Then, by rearranging the expression for $\alpha_{k}$, it is possible to show that $\alpha_{k}>0$ so long as $S_{s}$ is in the range

$$
\frac{\alpha_{s} \frac{f D_{v}}{f^{\prime} D_{v}^{\prime}}-1}{\alpha \frac{f D_{v}}{f^{\prime} D_{v}^{\prime}}-1+\left(1+b_{s}\right) /\left(1+\beta_{s}\right)}<S_{s}<3 .
$$

Since $\alpha_{s} f D_{v} / f^{\prime} D_{v}^{\prime}$ is within a few percent of $1, \alpha_{k}$ will be positive so long as $O(0.01) \lesssim S_{s}<3$. Since the saturation adjustment in the microphysical scheme generates deposition $\left(d r_{i} / d t>0\right.$ ) only when $S_{s} \approx 1$, equation (B25) and the positivity of $\alpha_{k}$ implies that $d r_{c}^{\prime} / d t>0$. This guarantees that no negative mixing ratios are ever generated. Therefore, it is safe to use equation (B25) in both ice clouds and mixed-phase clouds.

\section{B5. Sublimation of Ice}

[71] For sublimation of ice, we would need to know the isotopic composition of all the layers in the ice in order to correctly estimate the isotopic composition of sublimed water. It would be difficult to maintain a record of the isotopic composition of distinct layers of a single ice particle, accounting for the different effects of freezing, riming, and vapor deposition, and such a record would likely depend on the habit of the ice particle. Further, a consistent approach that would account for such layers and their sublimation across an assumed particle size distribution, such as that used in the present bulk microphysical scheme, is not obvious to the authors and would likely be prohibitively expensive. Therefore, we assume that ice sublimates at the ratio equal to its mean ratio,

$$
\frac{d r_{i}^{\prime}}{d t}=\frac{r_{i}^{\prime}}{r_{i}} \frac{d r_{i}}{d t}
$$

an approach that is also taken by Bony et al. [2008] among others. Equations for snow (graupel) are obtained from (B25) and (B27) by the replacement $r_{i} \rightarrow r_{s}\left(r_{g}\right)$.

[72] For the sensitivity study of layering (called LAYER), we assume that the sublimated water has the same isotopic content as the vapor that would deposit onto ice if the air were saturated. We also ensure that neither $r_{i}$ nor $r_{i}^{\prime}$ becomes negative, and that $r_{i}^{\prime}$ is zero whenever $r_{i}$ is zero. In addition, we do not want this scheme to generate ice that is heavier than the first layers of ice typically formed by deposition. In other words, we wish to restrict $r_{i}{ }^{\prime} / r_{i}$ in the sublimating ice from exceeding the maximum value of $r_{i}^{\prime} / r_{i}$ observed in the initial stages of ice cloud. When $r_{i}^{\prime} / r_{i}$ of the sublimating ice exceeds this maximum value, further sublimation will be specified in proportion to the mean ice content. This leads naturally to the following expression,

$$
\frac{d r_{i}^{\prime}}{d t}=\left\{\begin{array}{ll}
\max \left(-\frac{r_{i}^{\prime}}{\Delta t}, \alpha_{s} \frac{r_{v}^{\prime}}{r_{v}} \frac{d r_{i}}{d t}\right) & \text { if } r_{i}+\frac{d r_{i}}{d t} \Delta t>0 \text { and } \frac{r_{i}^{\prime}}{r_{i}}<\left(\frac{r_{i}^{\prime}}{r_{i}}\right)_{\max } \\
\frac{r_{i}^{\prime}}{r_{i}} \frac{d r_{i}}{d t} & \text { if } r_{i}+\frac{d r_{i}}{d t} \Delta t>0 \text { and } \frac{r_{i}^{\prime}}{r_{i}} \geq\left(\frac{r_{i}^{\prime}}{r_{i}}\right)_{\max } \\
-\frac{r_{i}^{\prime}}{\Delta t} & \text { if } r_{i}+\frac{d r_{i}}{d t} \Delta t=0
\end{array},\right.
$$

where $\Delta t$ is the model time step and we have used the fact that $\alpha_{k}=1$ when the air is saturated. To avoid spurious artifacts in the deuterium excess, we use the second case in equation (B28) for both isotopologues whenever either HDO's $r_{i}^{\prime} / r_{i}$ or $\mathrm{H}_{2}^{18} \mathrm{O}$ 's $r_{i}^{\prime} / r_{i}$ exceeds its threshold (taken to be a $\delta$ of 0 for either $\mathrm{HD}^{16} \mathrm{O}$ or $\mathrm{H}_{2}^{18} \mathrm{O}$ in the present study).

\section{B6. Summary of Isotope Microphysical Parameterizations}

[73] In summary, the diffusional exchange between the heavy vapor and the heavy condensates is governed by the following equations:

$$
\begin{array}{rlrl}
\frac{d r_{r}^{\prime}}{d t} & =C_{r} f^{\prime} D_{v}^{\prime}\left[\frac{r_{v}^{\prime}}{r_{v}} S_{l}-\frac{r_{r}^{\prime}}{r_{r}} \frac{1}{\alpha_{l}}\left(1+\left(b_{l}+\beta_{l}\right) \frac{S_{l}-1}{1+b_{l}}\right)\right] \\
r_{c}^{\prime} & =\frac{r_{v}^{\prime}+r_{c}^{\prime}}{1+\frac{r_{v}}{r_{c}} \frac{1}{\alpha_{l}}} & & \left(d r_{i, s, g} / d t \geq 0\right) \\
\frac{d r_{i, s, g}^{\prime}}{d t} & =\alpha_{s} \alpha_{k} \frac{r_{v}^{\prime}}{r_{v}} \frac{d r_{i, s, g}}{d t} & & \left(d r_{i, s, g} / d t<0\right) . \\
\frac{d r_{i, s, g}^{\prime}}{d t} & =\frac{r_{i, s, g}^{\prime}}{r_{i, s, g}} \frac{d r_{i, s, g}}{d t} &
\end{array}
$$

where $C_{r}$ is defined in (B20) and $\alpha_{k}$ is defined in (B26).

[74] Acknowledgments. We acknowledge Chris Bretherton, Dennis Hartmann, Qiang Fu, Tom Ackerman, and Gabriele Stiller for useful discussions concerning this work. Liz Moyer, Maximilien Bolot, Camille Risi, Joe Galewsky, and two anonymous reviewers provided valuable comments on an earlier version of this manuscript. We thank Justus Notholt for providing the observational data in Figure 11, Qiong Yang for providing the SHADOZ temperature data, and all of the SHADOZ participants for making that data set available. Thanks are also owed to Marat Khairoutdinov for sharing SAM with us and to Steve Krueger and Qiang Fu for sharing their improved treatment of the Bergeron process. This work was supported by NASA through grant NNX07AL47G.

\section{References}

Bony, S., C. Risi, and F. Vimeux (2008), Influence of convective processes on the isotopic composition $\left(\delta^{18} \mathrm{O}\right.$ and $\left.\delta \mathrm{D}\right)$ of precipitation and water vapor in the tropics: 1 . Radiative-convective equilibrium and Tropical Ocean-Global Atmosphere-Coupled Ocean-Atmosphere Response Experiment (TOGA-COARE) simulations, J. Geophys. Res., 113, D19305, doi:10.1029/2008JD009942.

Bretherton, C. S. (2007), Challenges in numerical modeling of tropical circulations, in The Global Circulation of the Atmosphere, edited by T. Schneider and A. H. Sobel, pp. 302-330, Princeton Univ. Press, Princeton, N. J.

Bretherton, C. S., P. N. Blossey, and M. E. Peters (2006), Interpretation of simple and cloud-resolving simulations of moist convection-radiation interaction with a mock-walker circulation, Theor. Comput. Fluid Dyn., 20(5-6), 421-442, doi:10.1007/s00162-006-0029-7.

Bretherton, C. S., R. Wood, R. C. George, D. Leon, G. Allen, and X. Zheng (2010), Southeast Pacific stratocumulus clouds, precipitation and boundary layer structure sampled along $20 \mathrm{~S}$ during VOCALS-REx, Atmos. Chem. Phys., 10, 10,639-10,654, doi:10.5194/acp-10-10639-2010. 
Brewer, A. W. (1949), Evidence for a world circulation provided by measurements of helium and water vapor distribution in the stratosphere, Q. J. R. Meteorol. Soc., 75(326), 351-363, doi:10.1002/ qj. 49707532603.

Chae, J. H., and S. C. Sherwood (2007), Annual temperature cycle of the tropical tropopause: A simple model study, J. Geophys. Res., 112, D19111, doi:10.1029/2006JD007956.

Chen, S.-H., and W.-Y. Sun (2002), A one-dimensional time dependent cloud model, J. Meteorol. Soc. Jpn., 80, 99-118.

Ciais, P., and J. Jouzel (1994), Deuterium and oxygen 18 in precipitation: Isotopic model, including mixed cloud processes, J. Geophys. Res., 99(D8), 16,793-16,803, doi:10.1029/94JD00412.

Corti, T., et al. (2008), Unprecedented evidence for deep convection hydrating the tropical stratosphere, Geophys. Res. Lett., 35, L10810, doi:10.1029/2008GL033641.

Dansgaard, W. (1964), Stable isotopes in precipitation, Tellus, 16, 436-468.

Dessler, A. E., and S. C. Sherwood (2003), A model of HDO in the tropical tropopause layer, Atmos. Chem. Phys., 3, 2173-2181, doi:10.5194/acp-32173-2003.

Folkins, I., P. Bernath, C. Boone, G. Lesins, N. Livesey, A. M. Thompson, K. Walker, and J. C. Witte (2006), Seasonal cycles of $\mathrm{O}_{3}, \mathrm{CO}$, and convective outflow at the tropical tropopause, Geophys. Res. Lett., 33, L16802, doi:10.1029/2006GL026602.

Forster, P., and K. P. Shine (1999), Stratospheric water vapour changes as a possible contributor to observed stratospheric cooling, Geophys. Res. Lett., 26(21), 3309-3312, doi:10.1029/1999GL010487.

Fueglistaler, S., A. E. Dessler, T. J. Dunkerton, I. Folkins, Q. Fu, and P. W. Mote (2009), Tropical tropopause layer, Rev. Geophys., 47, RG1004, doi:10.1029/2008RG000267.

Galewsky, J., and J. V. Hurley (2010), An advection-condensation model for subtropical water vapor isotopic ratios, J. Geophys. Res., 115, D16116, doi:10.1029/2009JD013651.

Galewsky, J., M. Strong, and Z. D. Sharp (2007), Measurements of water vapor D/H ratios from Mauna Kea, Hawaii, and implications for subtropical humidity dynamics, Geophys. Res. Lett., 34, L22808, doi:10.1029/ 2007GL031330.

Gedzelman, S., and R. Arnold (1994), Modeling the isotopic composition of precipitation, J. Geophys. Res., 99(D5), 10,455-10,471, doi:10.1029/93JD03518.

Gettelman, A., and C. R. Webster (2005), Simulations of water isotope abundances in the upper troposphere and lower stratosphere and implications for stratosphere troposphere exchange, J. Geophys. Res., 110, D17301, doi:10.1029/2004JD004812.

Grabowski, W. W., J.-I. Yano, and M. Moncrieff (2000), Cloud resolving modeling of tropical circulations driven by large-scale SST gradients, J. Atmos. Sci., 57, 2022-2039.

Hartmann, D. L., J. R. Holton, and Q. Fu (2001), The heat balance of the tropical tropopause, cirrus, and stratospheric dehydration, Geophys. Res. Lett., 28(10), 1969-1972, doi:10.1029/2000GL012833.

Heymsfield, A. J., and L. J. Donner (1990), A scheme for parameterizing ice-cloud water content in general circulation models, J. Atmos. Sci., 47, 1865-1877.

Holton, J. R., and A. Gettelman (2001), Horizontal transport and the dehydration of the stratosphere, Geophys. Res. Lett., 28(14), 2799-2802, doi:10.1029/2001GL013148.

Houze, R. A. (1993), Cloud Dynamics, Academic Press, San Diego, Calif.

Jensen, E. J., L. Pfister, T.-P. Bui, P. Lawson, and D. Baumgardner (2010), Ice nucleation and cloud microphysical properties in tropical tropopause layer cirrus, Atmos. Chem. Phys., 10, 1369-1384.

Jouzel, J., and L. Merlivat (1984), Deuterium and oxygen 18 in precipitation: Modeling of the isotopic effects during snow formation, J. Geophys. Res., 89(D7), 11,749-11,757, doi:10.1029/JD089iD07p11749.

Jouzel, J., L. Merlivat, and E. Roth (1975), Isotopic study of hail, J. Geophys. Res., 80(36), 5015-5030, doi:10.1029/JC080i036p05015.

Khairoutdinov, M. F., and D. A. Randall (2003), Cloud resolving modeling of the ARM summer 1997 IOP: Model formulation, results, uncertainties, and sensitivities, J. Atmos. Sci., 60, 607-625.

Kirk-Davidoff, D. B., E. Hintsa, J. Anderson, and D. W. Keith (1999), The effect of climate change on ozone depletion through changes in stratospheric water vapor, Nature, 402, 399-401.

Krueger, S. K., Q. Fu, K. N. Liou, and H.-N. S. Chin (1995), Improvements in an ice-phase microphysics parameterization for use in numerical simulations of tropical convection, J. Appl. Meteorol., 34, 281-287.

Kuang, Z., G. C. Toon, P. O. Wennberg, and Y. L. Yung (2003), Measured $\mathrm{HDO} / \mathrm{H}_{2} \mathrm{O}$ ratios across the tropical tropopause, Geophys. Res. Lett., 30(7), 1372, doi:10.1029/2003GL017023.

Lin, Y.-L., R. D. Farley, and H. D. Orville (1983), Bulk parameterization of the snow field in a cloud model, J. Clim. Appl. Meteorol., 22, 1065-1092.
Merlivat, L., and J. Jouzel (1979), Global climatic interpretation of the deuterium-oxygen 18 relationship for precipitation, J. Geophys. Res., 84(C8), 5029-5033, doi:10.1029/JC084iC08p05029.

Mote, P. W., K. H. Rosenlof, J. R. Holton, R. S. Harwood, and J. W. Waters (1995), Seasonal variations of water vapor in the tropical lower stratosphere, Geophys. Res. Lett., 22(9), 1093-1096, doi:10.1029/95GL01234.

Moyer, E. J., F. W. Irion, Y. L. Yung, and M. R. Gunson (1996), ATMOS stratospheric deuterated water and implications for troposphere-stratosphere transport, Geophys. Res. Lett., 23(17), 2385-2388, doi:10.1029/ 96GL01489.

Nassar, R., P. F. Bernath, C. D. Boone, A. Gettelman, S. D. Mcleod, and C. P. Rinsland (2007), Variability in $\mathrm{HDO} / \mathrm{H}_{2} \mathrm{O}$ abundance ratios in the tropical tropopause layer, J. Geophys. Res., 112, D21305, doi:10.1029/ 2007JD008417.

Notholt, J., et al. (2010), Trend in ice moistening the stratosphereConstraints from isotope data of water and methane, Atmos. Chem. Phys, 10, 201-207.

Payne, V. H., D. Noone, A. Dudhia, C. Piccolo, and R. G. Grainger (2007), Global satellite measurements of $\mathrm{HDO}$ and implications for understanding the transport of water vapour into the stratosphere, $Q . J$. R. Meteorol. Soc., 133(627), 1459-1471, doi:10.1002/qj.127.

Read, W. G., M. J. Schwartz, A. Lambert, H. Su, N. J. Livesey, W. H. Daffer, and C. D. Boone (2008), The roles of convection, extratropical mixing, and in-situ freeze-drying in the tropical tropopause layer, Atmos. Chem. Phys., 8, 6051-6067.

Rosenlof, K. H., et al. (2001), Stratospheric water vapor increases over the past half-century, Geophys. Res. Lett., 28(7), 1195-1198, doi:10.1029/ 2000GL012502.

Sayres, D. S., et al. (2010), The influence of convection on the water isotopic composition of the tropical tropopause layer and tropical stratosphere, J. Geophys. Res., 115, D00J20, doi:10.1029/2009JD013100.

Schmidt, G. A., G. Hoffmann, D. T. Shindell, and Y. Hu (2005), Modeling atmospheric stable water isotopes and the potential for constraining cloud processes and stratosphere-troposphere water exchange, J. Geophys. Res., 110, D21314, doi:10.1029/2005JD005790.

Schmitt, C. G., and A. J. Heymsfield (2009), The size distribution and mass-weighted terminal velocity of low-latitude tropopause cirrus crystal populations, J. Atmos. Sci., 66, 2013-2028, doi:10.1175/ 2009JAS3004.1.

Sherwood, S. C., and A. E. Dessler (2001), A model for transport across the tropical tropopause, J. Atmos. Sci., 58, 765-779.

Shindell, D. T. (2001), Climate and ozone response to increased stratospheric water vapor, Geophys. Res. Lett., 28(8), 1551-1554, doi:10.1029/1999GL011197.

Skamarock, W. C., and J. B. Klemp (2008), A time-split nonhydrostatic atmospheric model for weather research and forecasting applications, J. Comput. Phys., 227, 3465-3485, doi:10.1016/j.jcp.2007.01.037.

Smith, J. A., A. S. Ackerman, E. J. Jensen, and O. B. Toon (2006), Role of deep convection in establishing the isotopic composition of water vapor in the tropical transition layer, Geophys. Res. Lett., 33, L06812, doi:10.1029/2005GL024078.

Solomon, S., K. Rosenlof, R. Portmann, J. Daniel, S. Davis, T. Sanford, and G.-K. Plattner (2010), Contributions of stratospheric water vapor to decadal changes in the rate of global warming, Science, 327(5970), 1219-1223, doi:10.1126/science.1182488.

Spichtinger, P., K. Gierens, and W. Read (2003), The global distribution of ice-supersaturated regions as seen by the Microwave Limb Sounder, Q. J. R. Meteorol. Soc., 129(595), 3391-3410, doi:10.1256/qj.02.141.

Srivastava, R. C., and J. L. Coen (1992), New explicit equations for the accurate calculation of the growth and evaporation of hydrometeors by the diffusion of water vapor, J. Atmos. Sci., 49, 1643-1651.

St Clair, J. M., et al. (2008), A new photolysis laser-induced fluorescence instrument for the detection of $\mathrm{H} 2 \mathrm{O}$ and $\mathrm{HDO}$ in the lower stratosphere, Rev. Sci. Instrum., 79(6), 064101, doi:10.1063/1.2940221.

Steinwagner, J., S. Fueglistaler, G. Stiller, T. von Clarmann, M. Kiefer, P.-P. Borsboom, A. van Delden, and T. Rockmann (2010), Tropical dehydration processes constrained by the seasonality of stratospheric deuterated water, Nat. Geosci., 3(4), 262-266, doi:10.1038/ngeo822.

Thompson, A. J. W., et al. (2003), Southern Hemisphere Additional Ozonesondes (SHADOZ) 1998-2000 tropical ozone climatology: 1. Comparison with Total Ozone Mapping Spectrometer (TOMS) and ground-based measurements, J. Geophys. Res., 108(D2), 8238, doi:10.1029/2001JD000967.

Thompson, G., P. R. Field, R. M. Rasmussen, and W. D. Hall (2008), Explicit forecasts of winter precipitation using an improved bulk microphysics scheme. Part II: Implementation of a new snow parameterization, Mon. Weather Rev., 136, 5095-5115. 
Tompkins, A. M., and G. C. Craig (1998), Time-scales of adjustment to radiative-convective equilibrium in the tropical atmosphere, $Q . J . R$. Meteorol. Soc., 124(552), 2693-2713.

Webster, C. R., and A. J. Heymsfield (2003), Water isotope ratios D/H, ${ }^{18} \mathrm{O} /{ }^{16} \mathrm{O},{ }^{17} \mathrm{O} /{ }^{16} \mathrm{O}$ in and out of clouds map dehydration pathways, Science, 302(5651), 1742-1745, doi:10.1126/science.1089496.

Yang, Q., Q. Fu, J. Austin, A. Gettelman, F. Li, and H. Vömel (2008), Observationally derived and general circulation model simulated tropical stratospheric upward mass fluxes, J. Geophys. Res., 113, D00B07, doi:10.1029/2008JD009945.
Zeng, X., et al. (2007), Evaluating clouds in long-term cloud-resolving model simulations with observational data, J. Atmos. Sci., 64, 41534177, doi:10.1175/2007JAS2170.1.

P. N. Blossey, Atmospheric Sciences, University of Washington, PO Box 351640, Seattle, WA 98195-1640, USA. (pblossey@u.washington.edu)

Z. Kuang and D. M. Romps, Department of Earth and Planetary Sciences, Harvard University, 20 Oxford St., Cambridge, MA 02138, USA. (kuang@fas.harvard.edu; davidromps@gmail.com) 